\title{
TUSUTトPBกLU HISTORY
}

กU\$h4 しU<UヤtS3Uし*

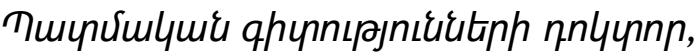

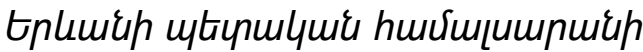

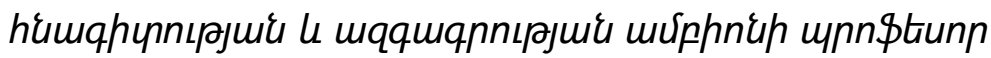
rafiknahapetyan@mail.ru

DOI: 10.52853/18294073-20213.27-5

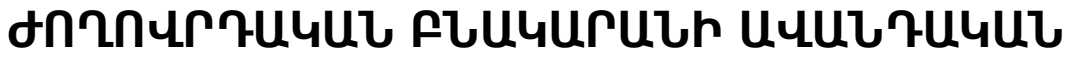 cUUULhrutrh ShTtre U2aนhenhU (XIX भUก - XX भUrUU५hRf)}

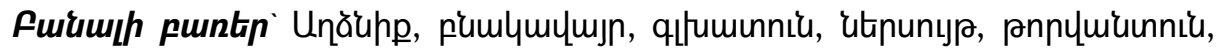
tupuiup quulun, Surunnhl:

\section{Utpuidnıрjnı\&}

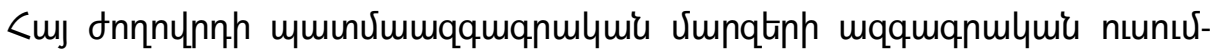

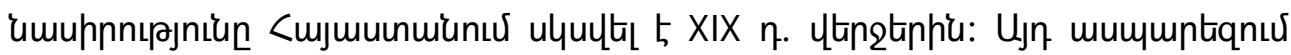

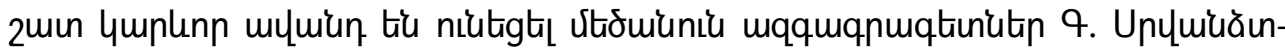

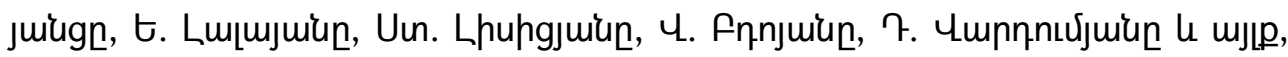

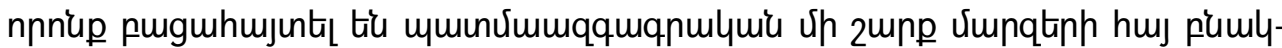

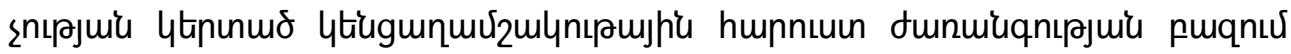

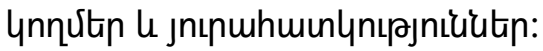

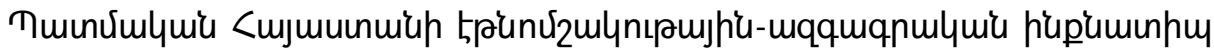

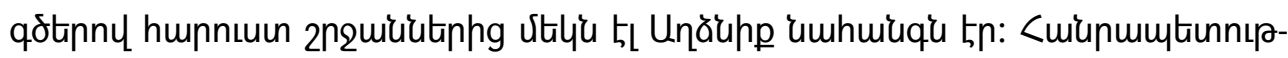

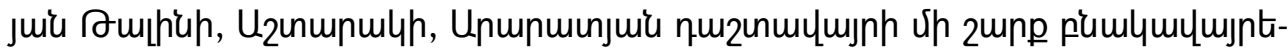

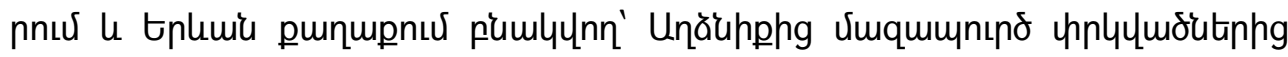

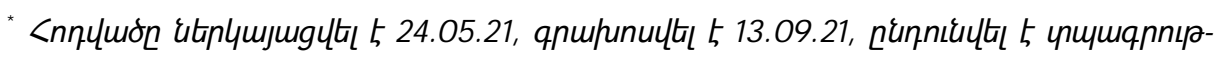
јயuध 19.1121: 


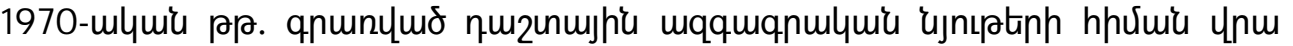

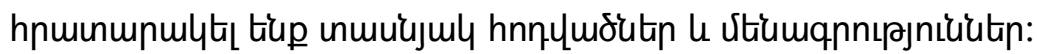

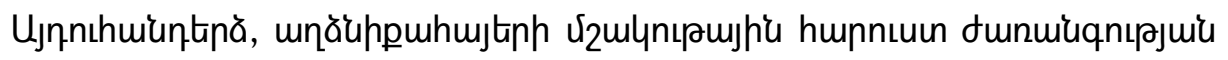

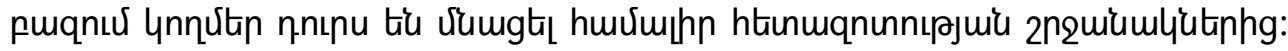

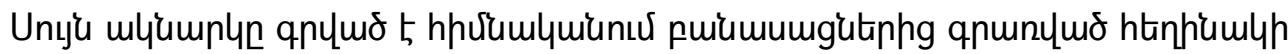

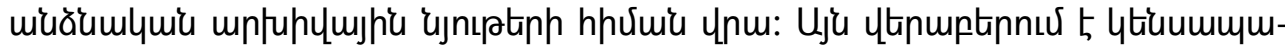

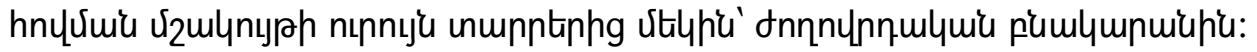

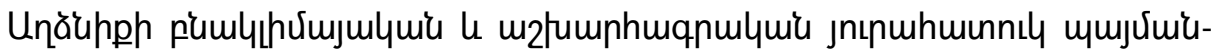

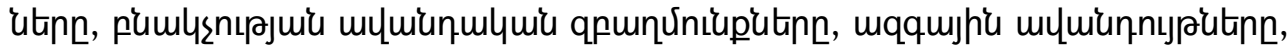

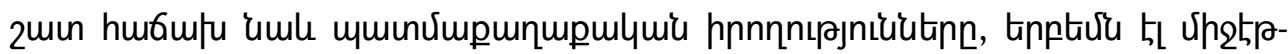

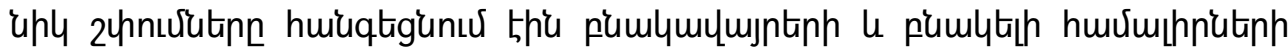

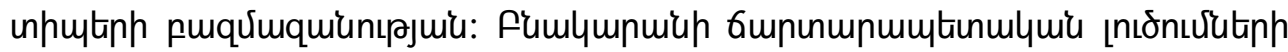

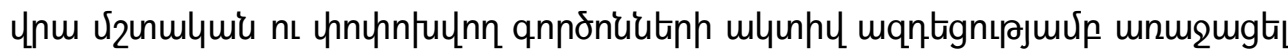

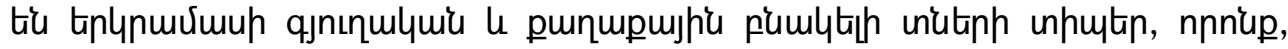

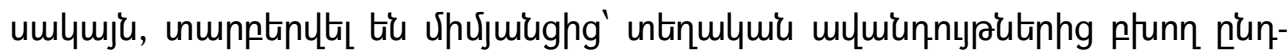

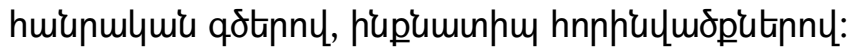

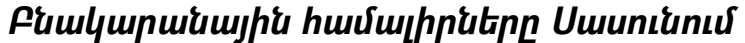

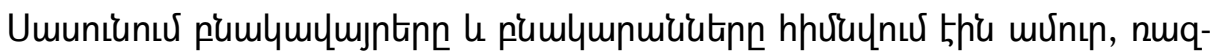

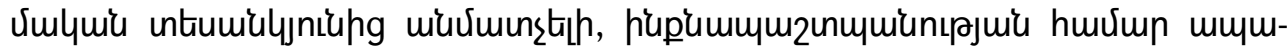

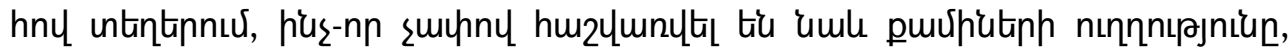
mplumhujug

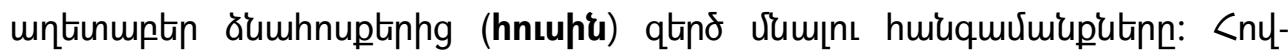

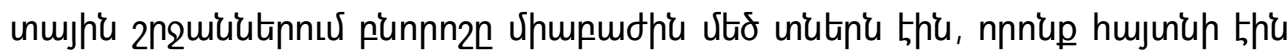

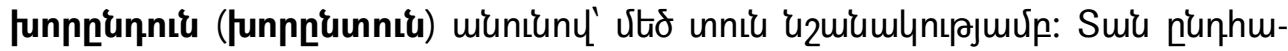

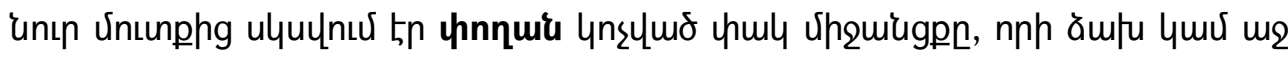

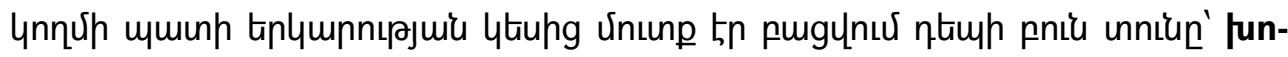

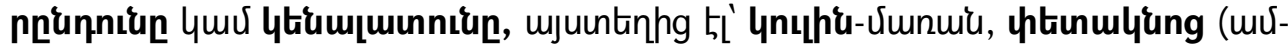

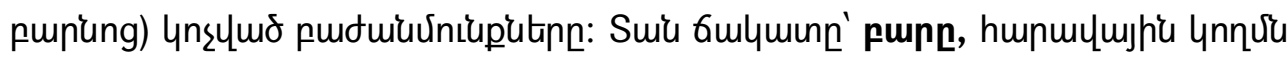

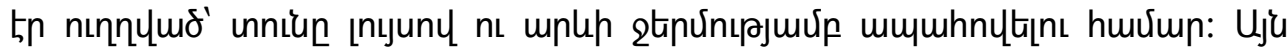

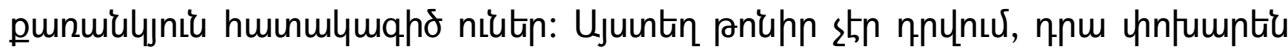

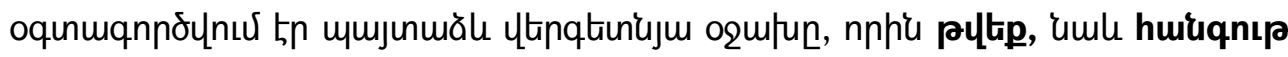

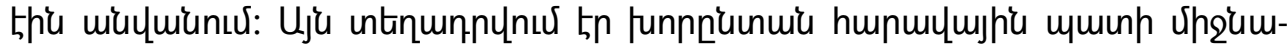

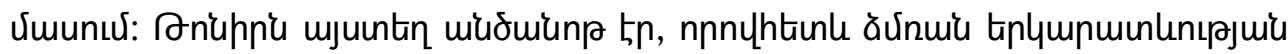

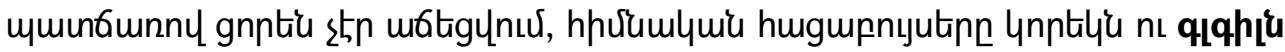


Umhumbtunjuis $\mathrm{n}$.

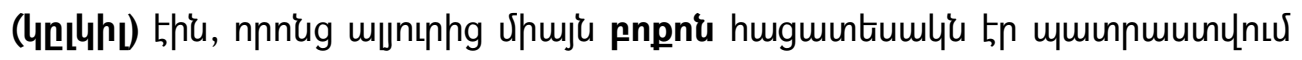
oquiu-pцtiph цnu:

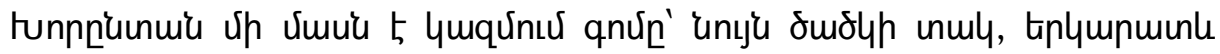

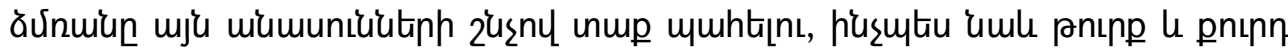

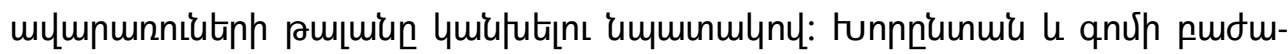

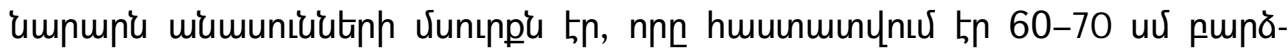

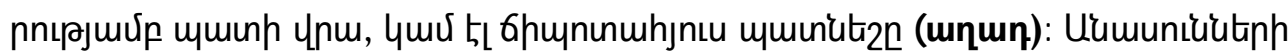

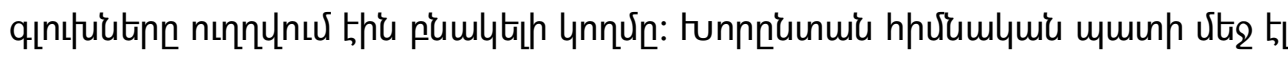

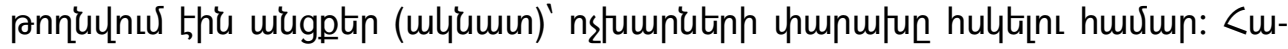

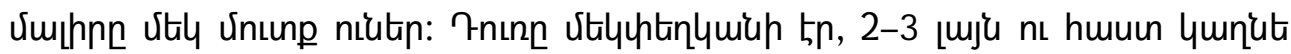

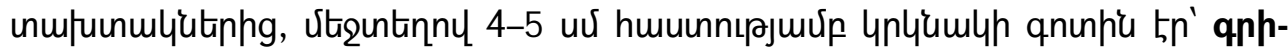

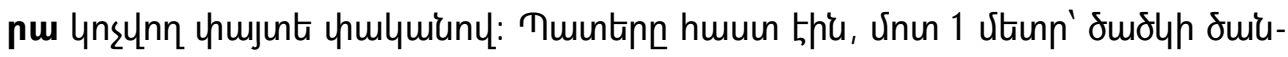

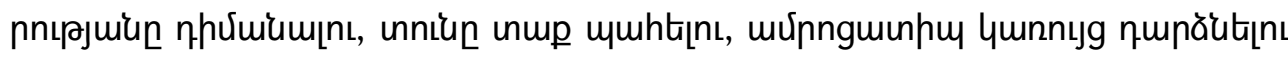

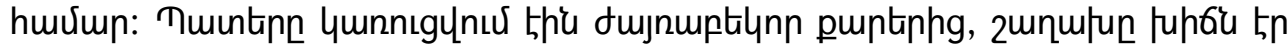

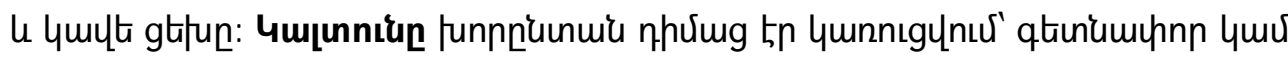

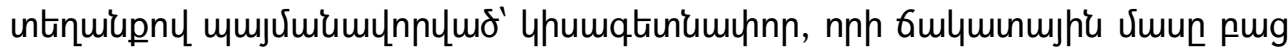

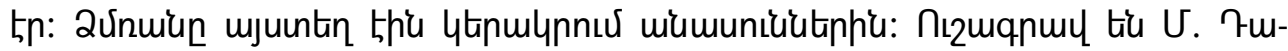

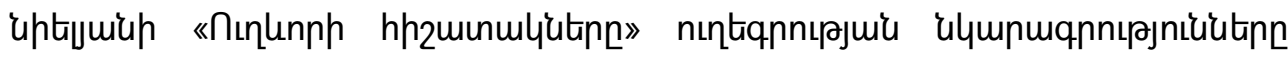

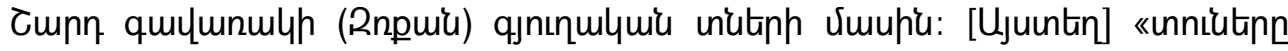

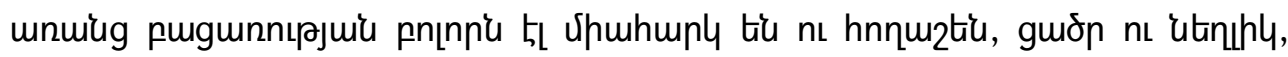

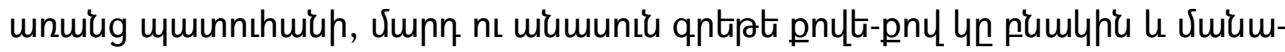

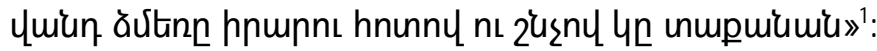

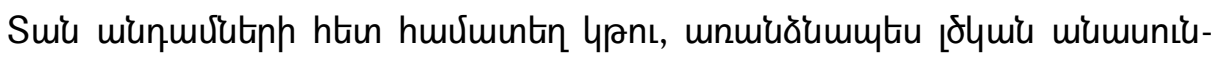

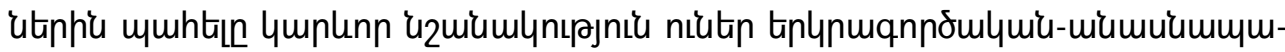

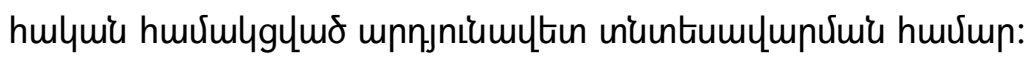

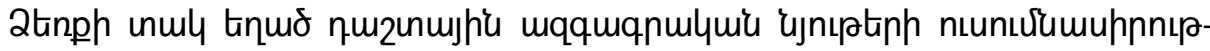

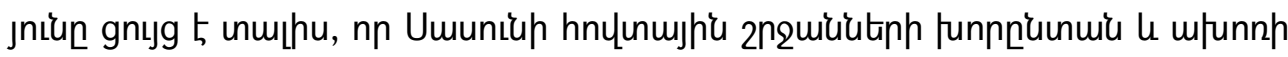

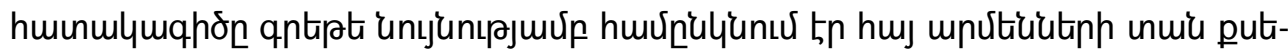

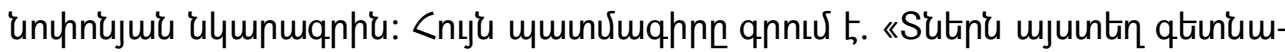

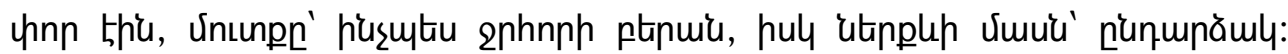

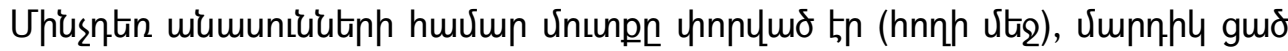

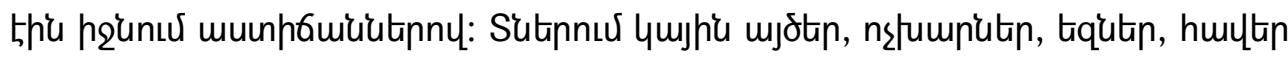

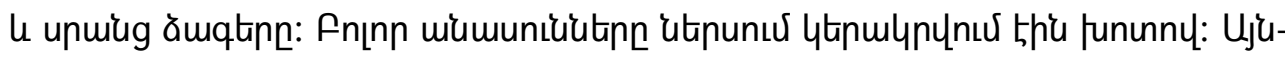

\footnotetext{
${ }^{1}$ Stíu «Unlutipp» 1903, № 5221:
} 


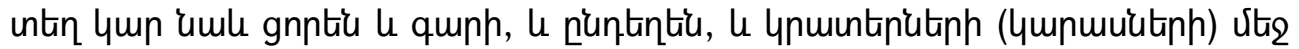

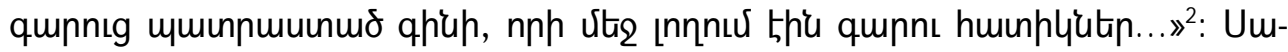

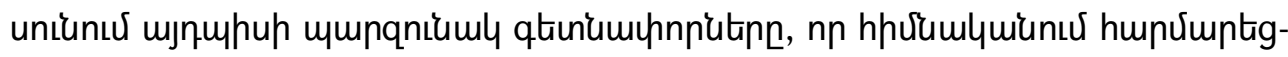

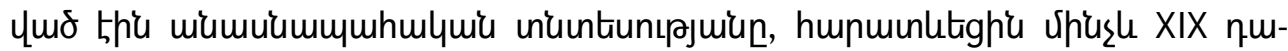
nuclting \& XX nunuulyhqp ${ }^{3}$ :

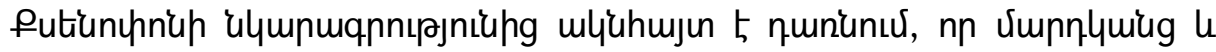

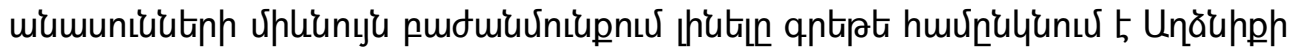

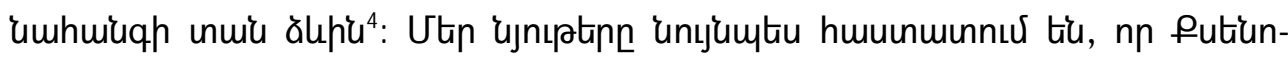

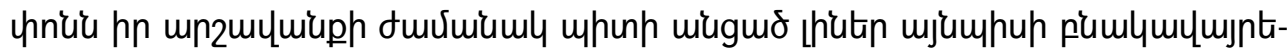

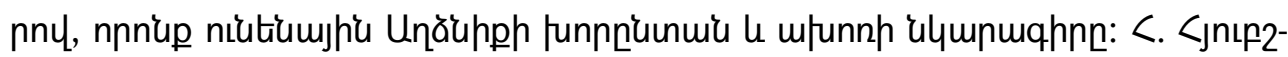

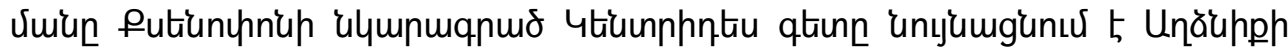

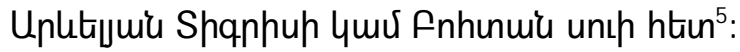

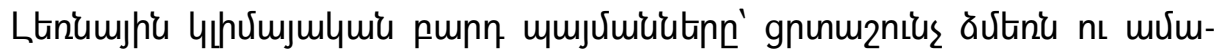

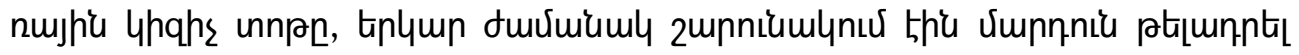

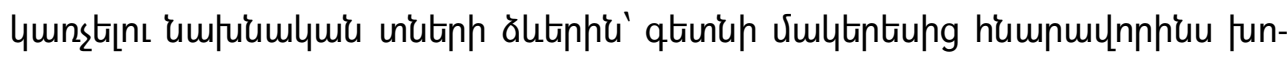

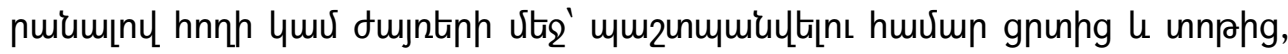

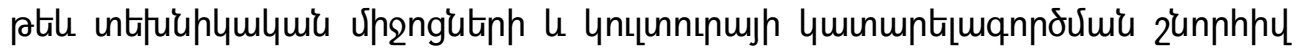

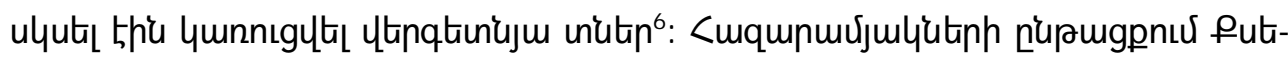

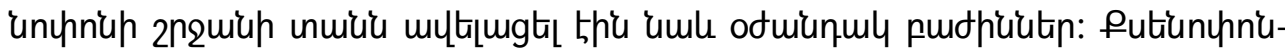

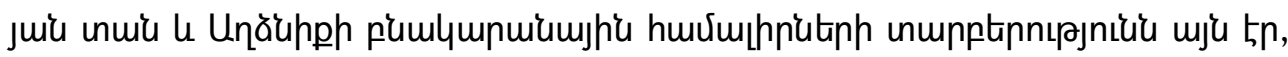

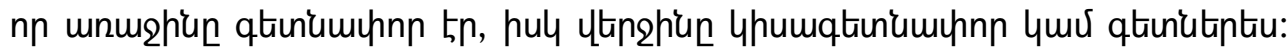

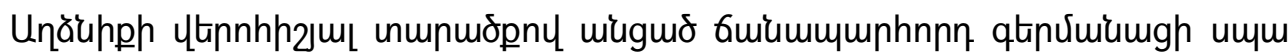

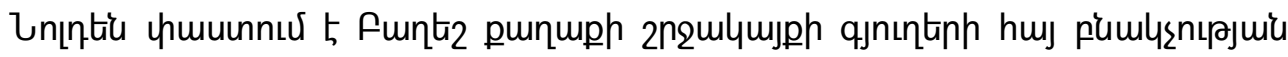

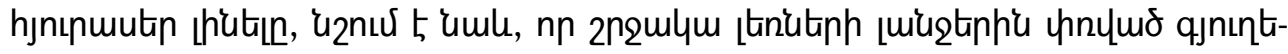

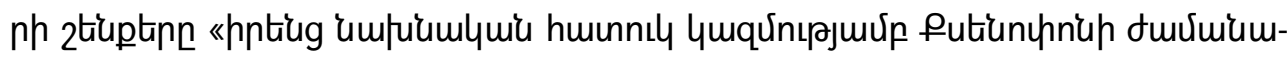

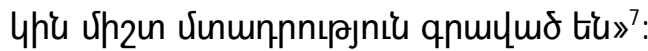

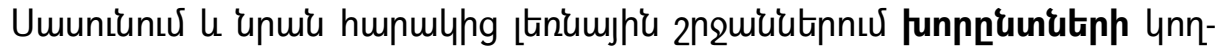

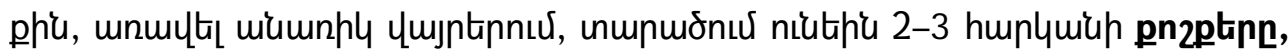

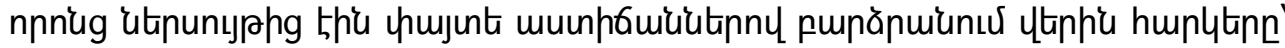

2 Putiununu 1970, 97:

3 «Unmpu» huiuntiu 1894-95, q. U, 52 88: 〈Uরun. «Lnưu»» 1893, q. U, «Unămquiup» 1894, № 140:

${ }^{4}$ Stíu Uuhumbtonjuí 1973, 236-243:

${ }^{5}$ Stíu <jnıp2ưuí 1907, 12:

${ }^{6}$ Stíu Uuúúntijuut 1941, h. 2, 193:

7 «<uiuntu uvưoptiuj» 1896, № 9: 
Umhumbtunjuis $\mathrm{n}$.

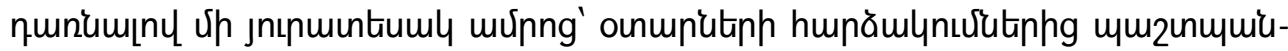

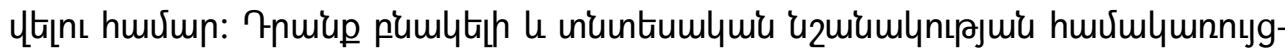

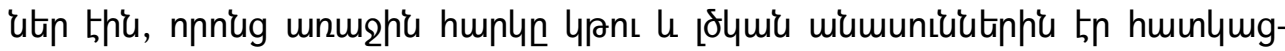

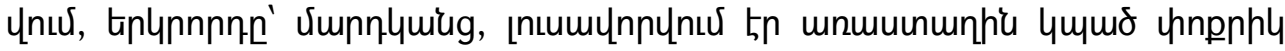

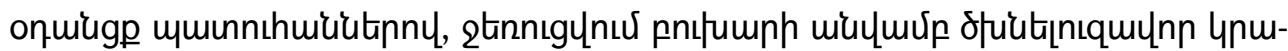

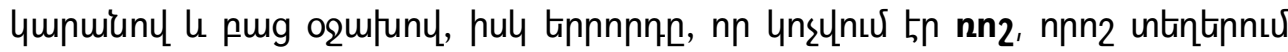

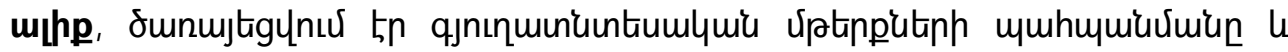

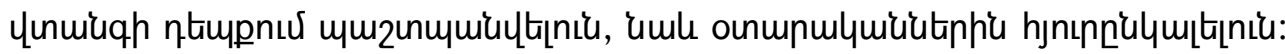

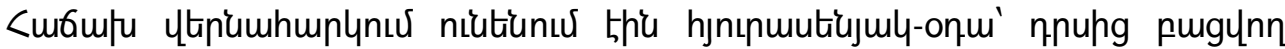

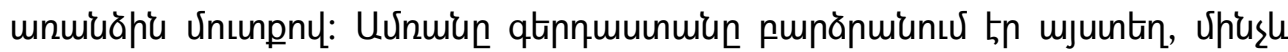

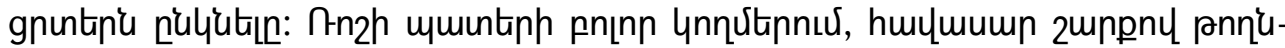

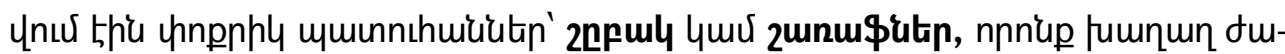

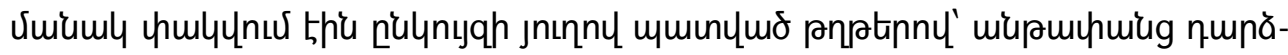

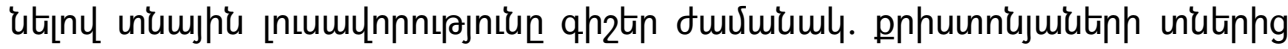

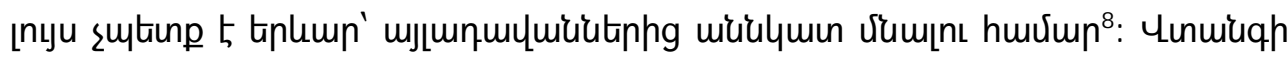

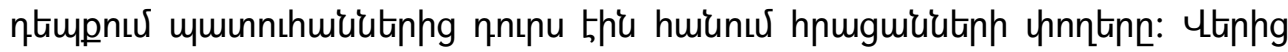

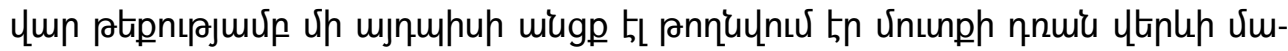

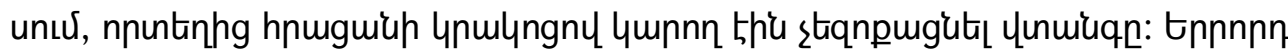

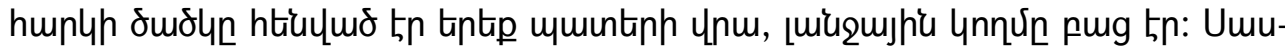

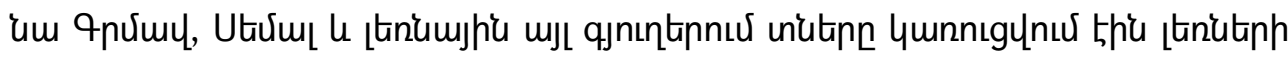

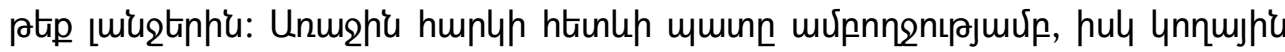

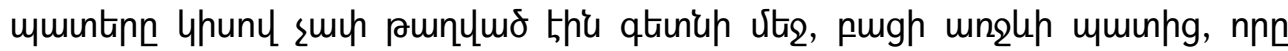

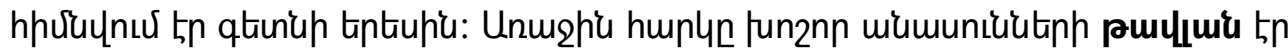

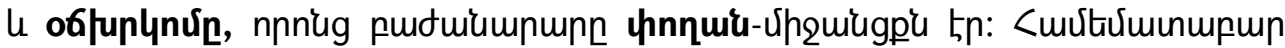

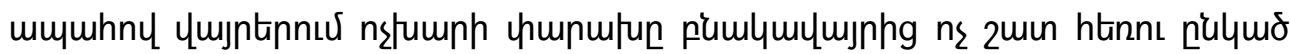

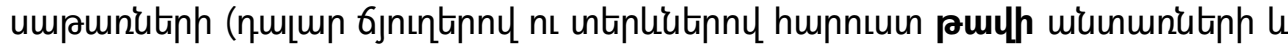

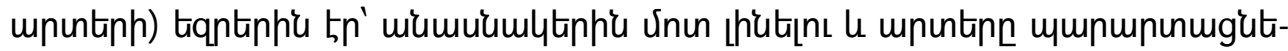

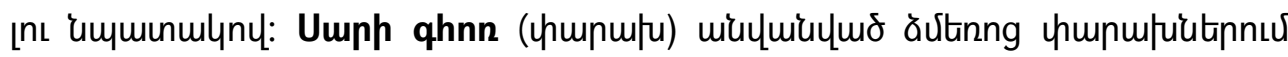
huб

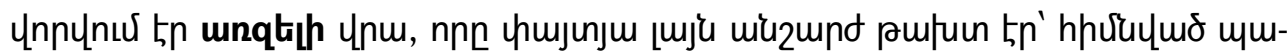

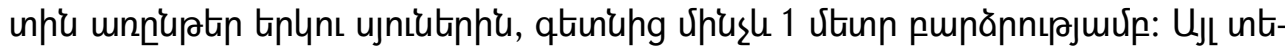

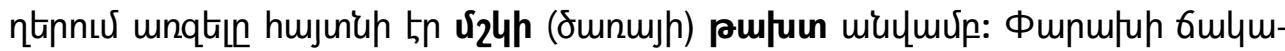

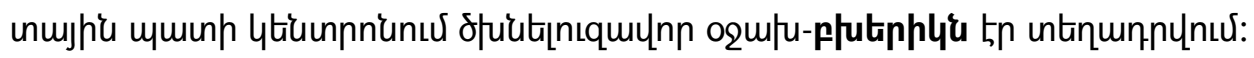

\footnotetext{
${ }^{8}$ Stíu Shqnuí Ulyniın 1950, h. U, 155:
} 


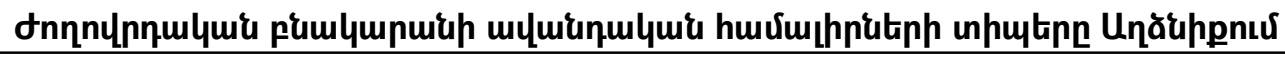

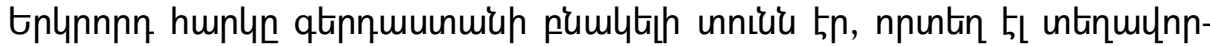

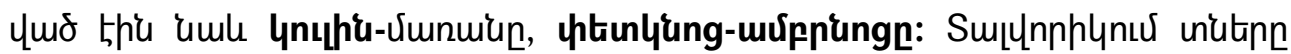

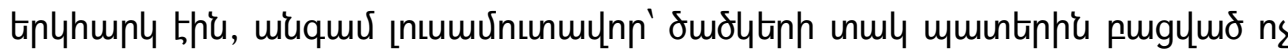

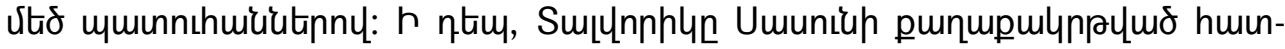

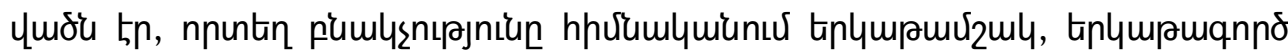

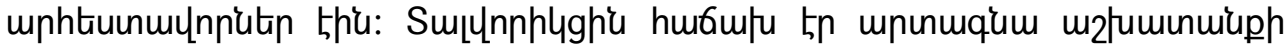

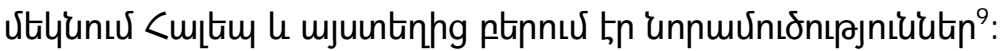

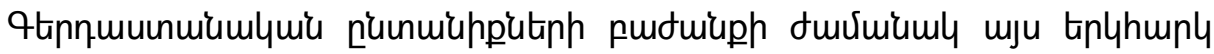

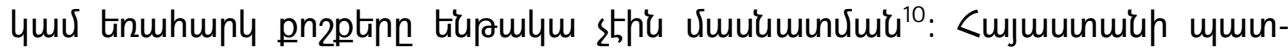

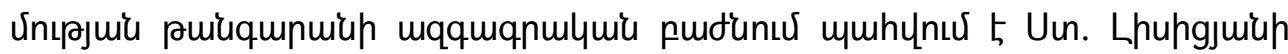

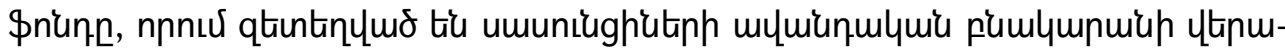

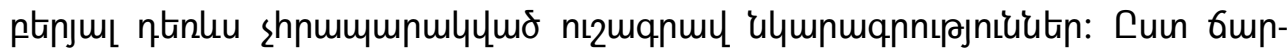

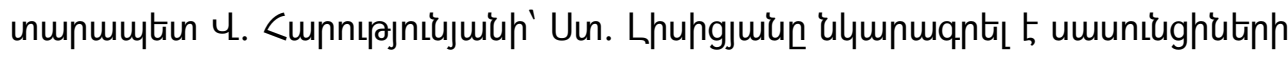

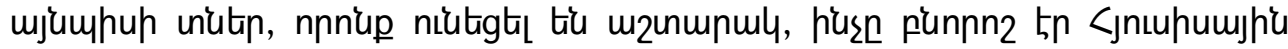

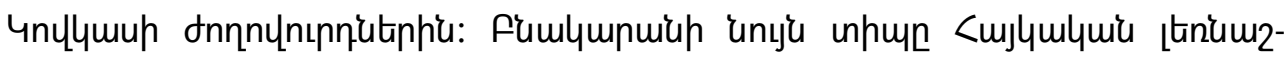

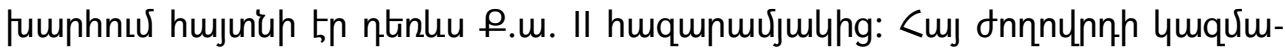

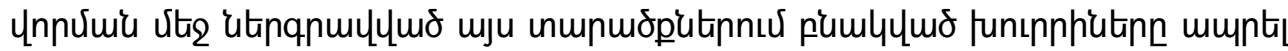

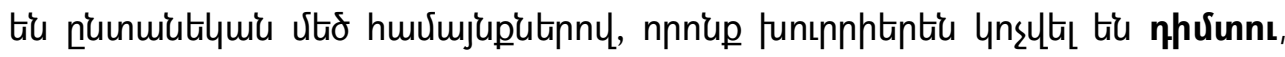

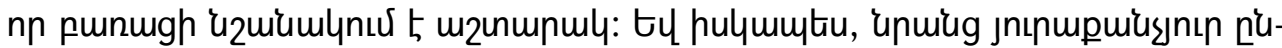

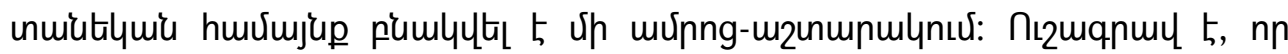

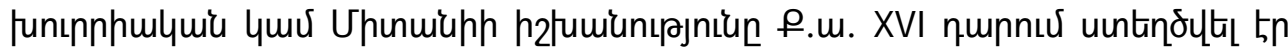

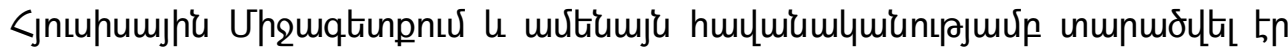

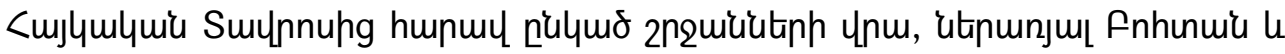

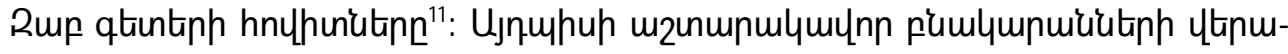

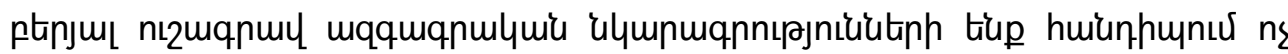

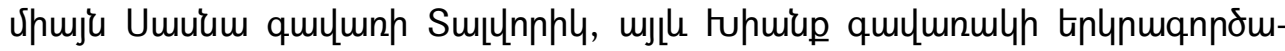

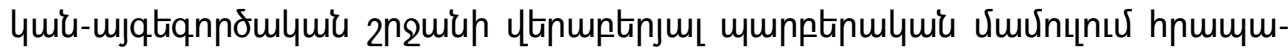
puly

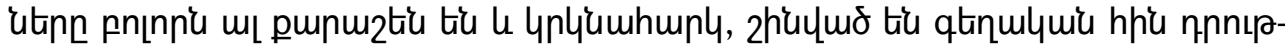

${ }^{9} \mathrm{St}^{\prime} u$ «U 2 mul» 1894, № 118:

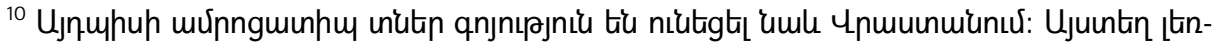

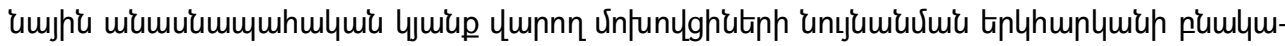

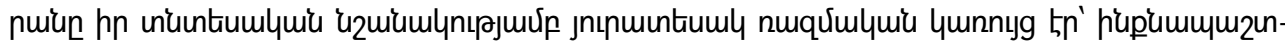

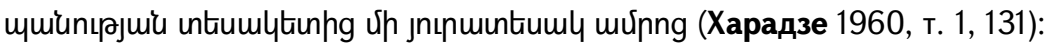

${ }^{11}$ St'u ๆjulynuny 1971, h. 1, 182: 
Umhumbtunjuis $\mathrm{n}$.

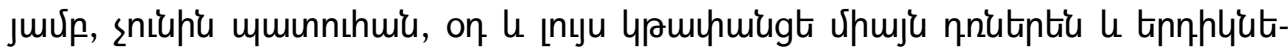

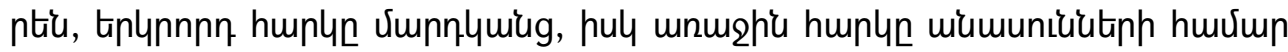

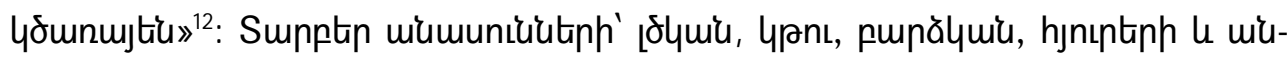

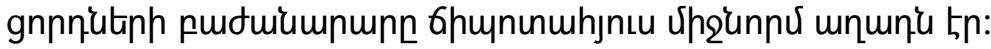

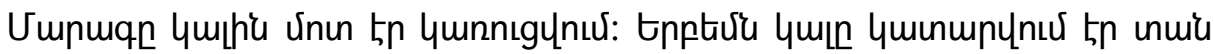

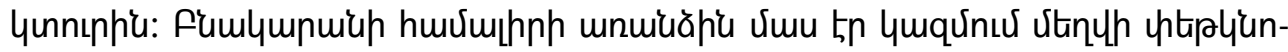

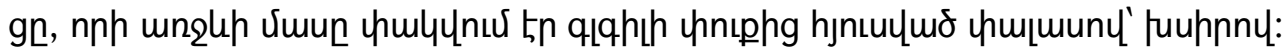

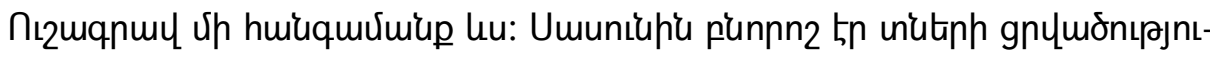

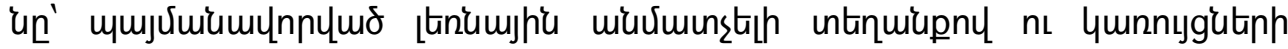

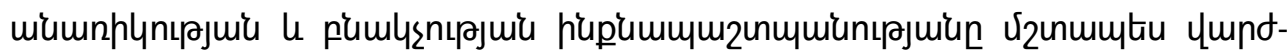

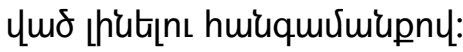

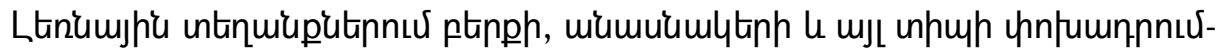

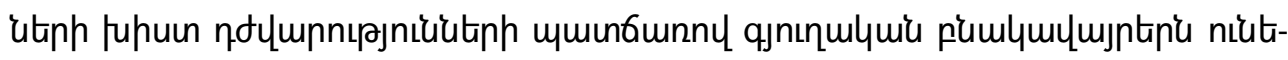

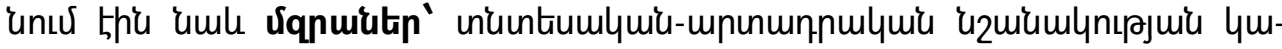

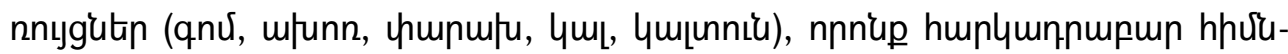

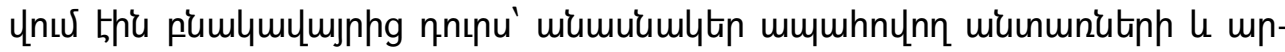

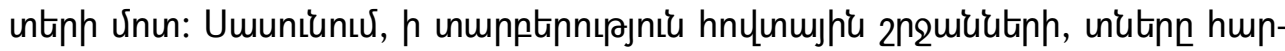

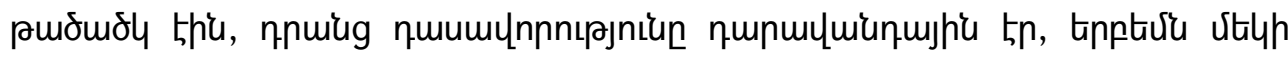

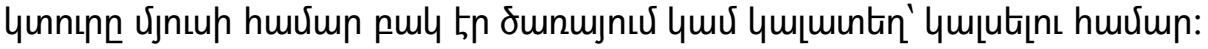

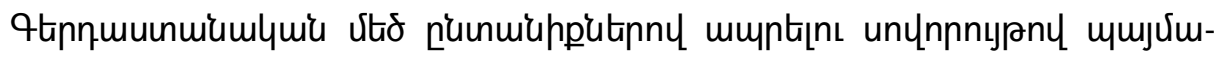

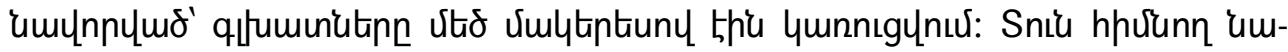

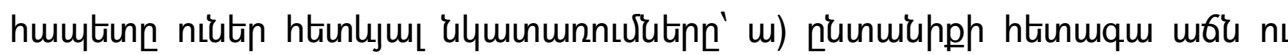

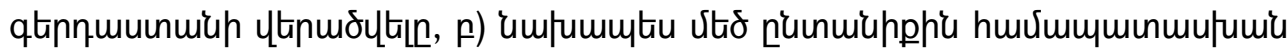

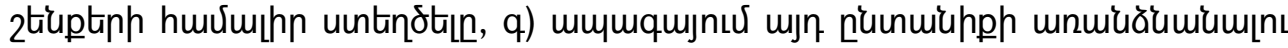

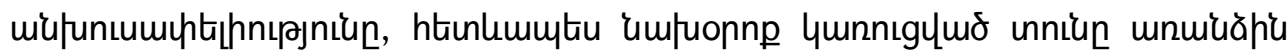

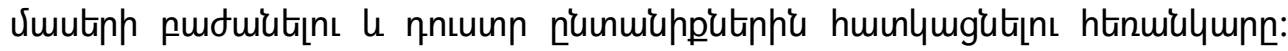

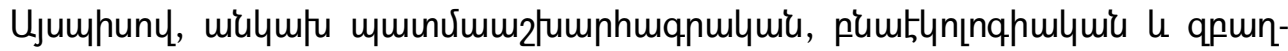

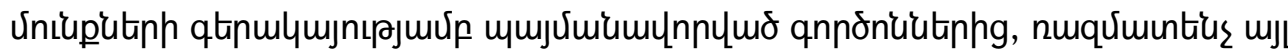

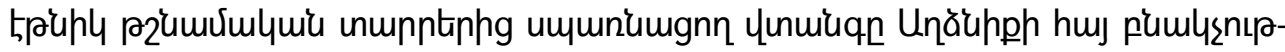

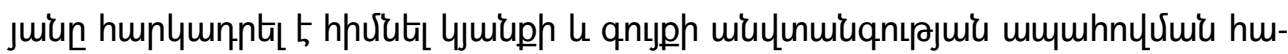

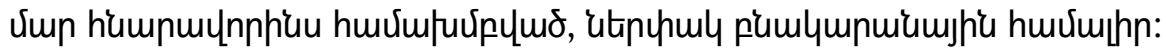

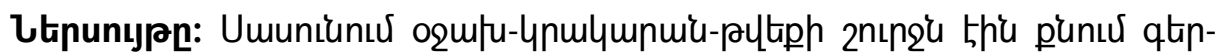

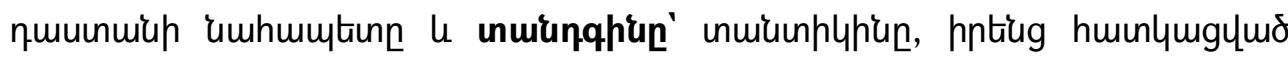

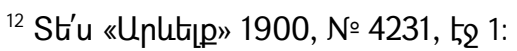




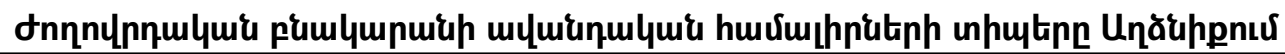

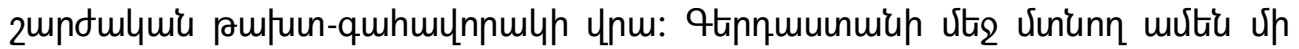

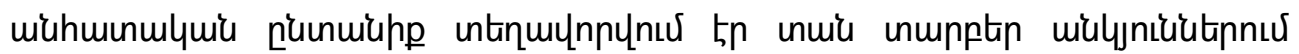

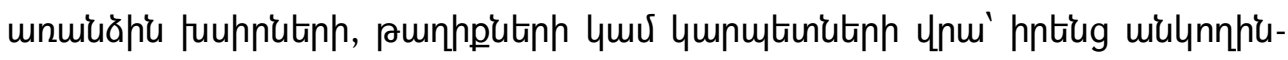

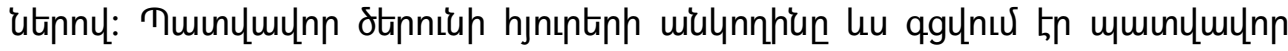

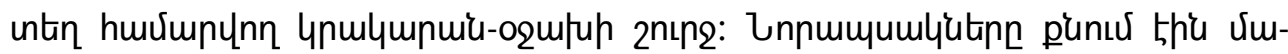

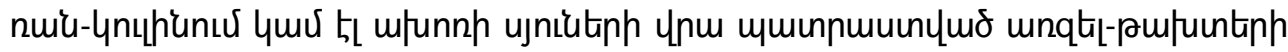

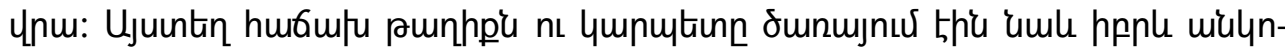

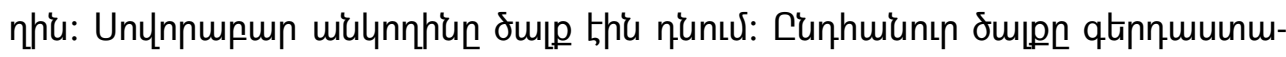

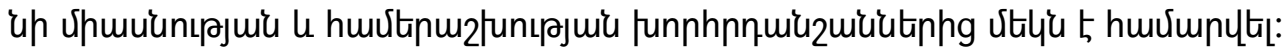

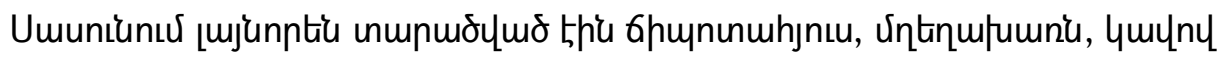

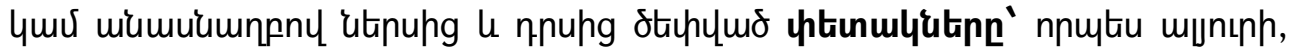

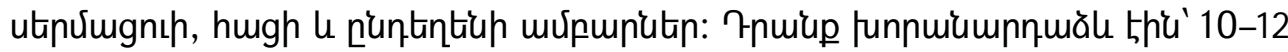

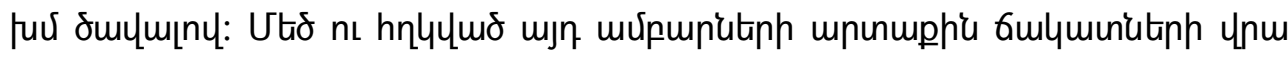

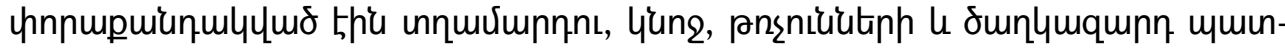

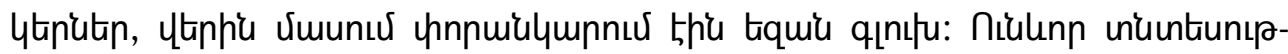

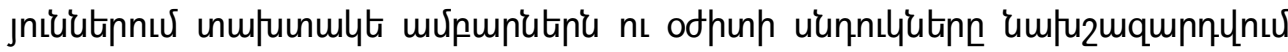

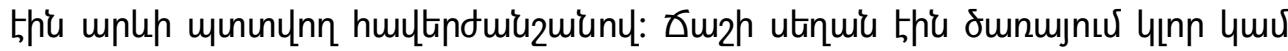

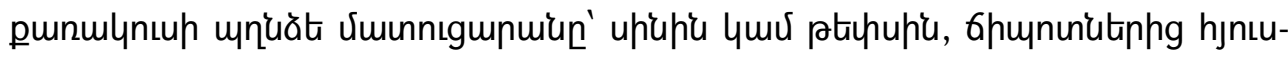
ч

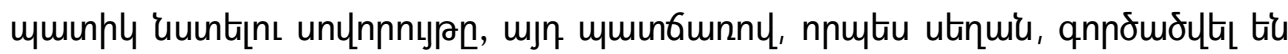

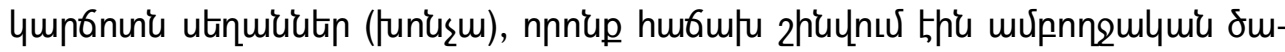

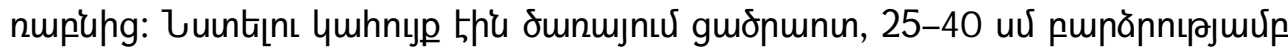

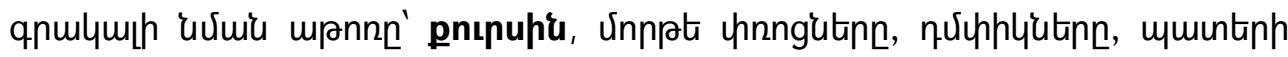

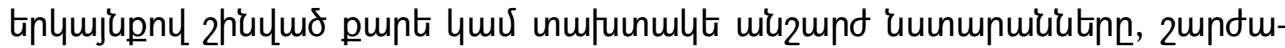

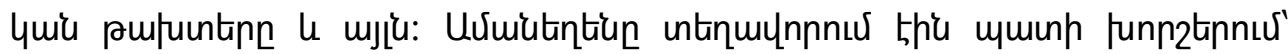

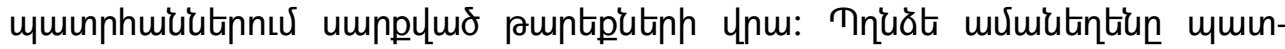

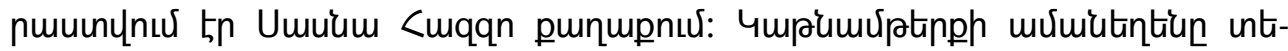

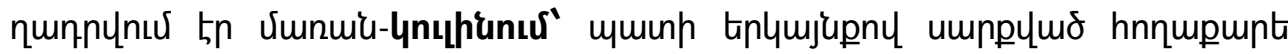

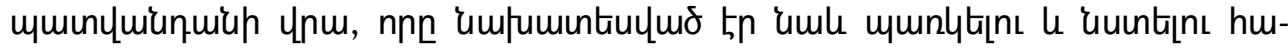

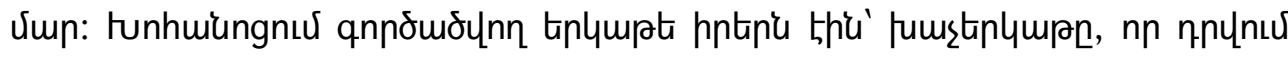

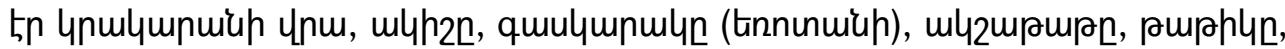

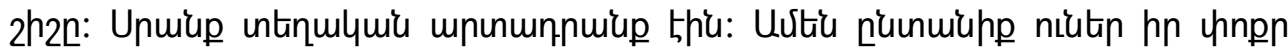

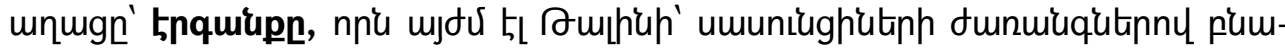

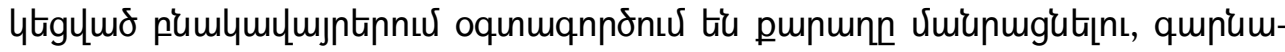

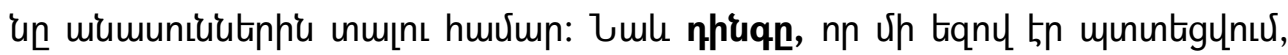


Umhumbtunjuis $\mathrm{n}$.

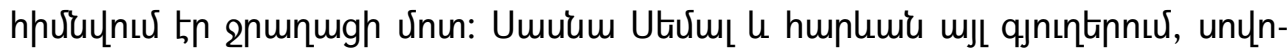

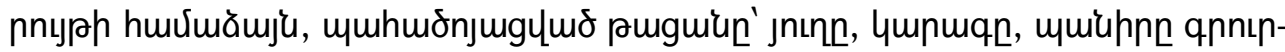

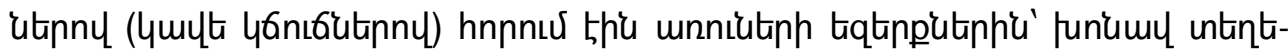

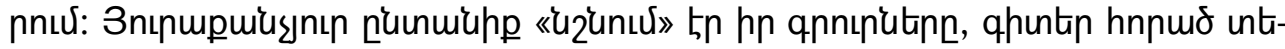

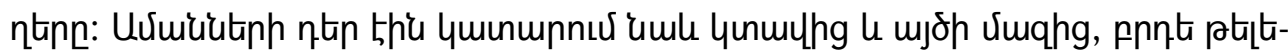

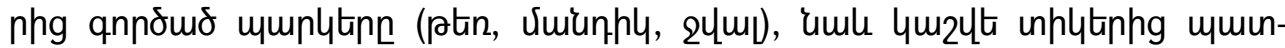

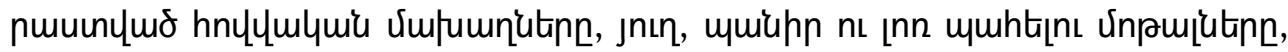
qhuns $\mathrm{l}$ onns unplyting $\mathrm{l}$ mృ

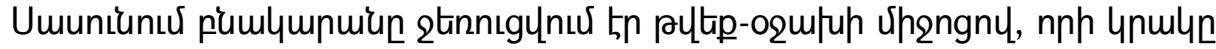

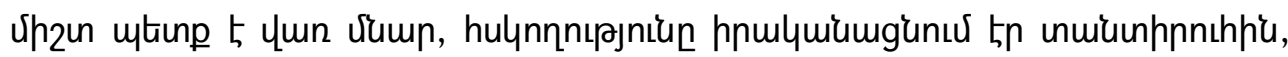

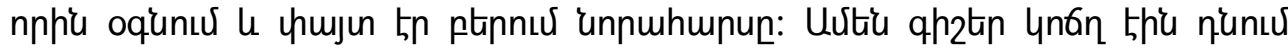

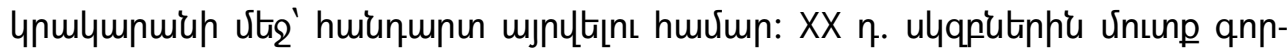

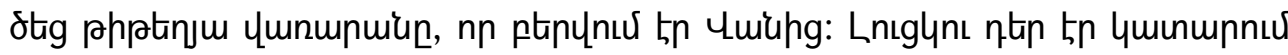

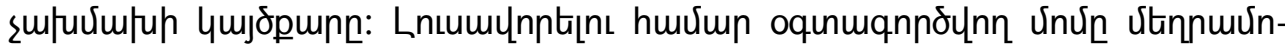

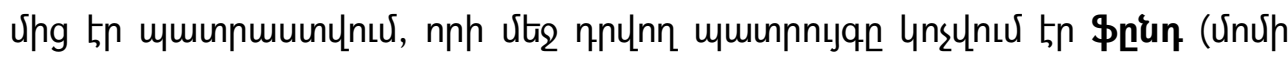

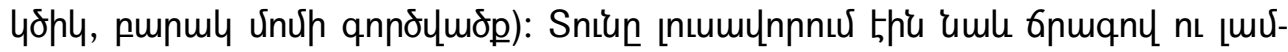

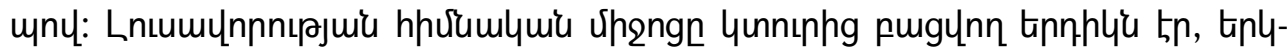

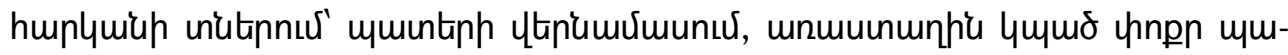
unnthuiuutinn:

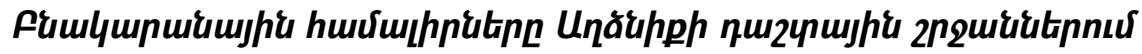

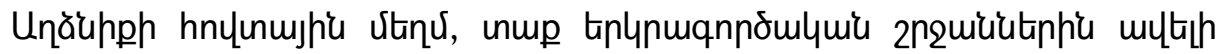

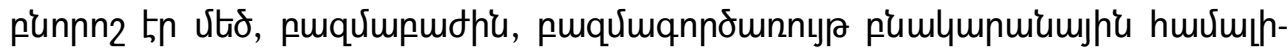

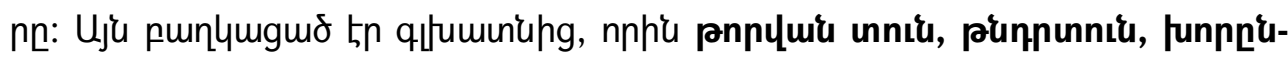

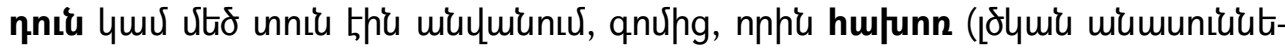

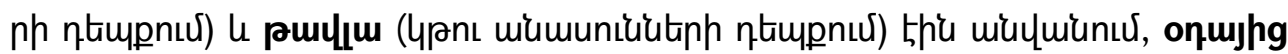

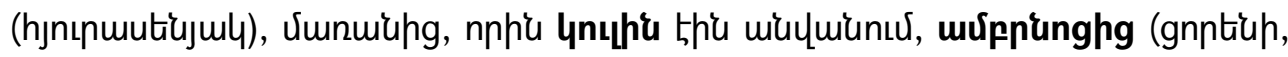

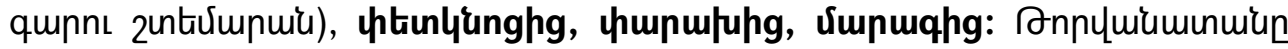
oqunuqnnoy

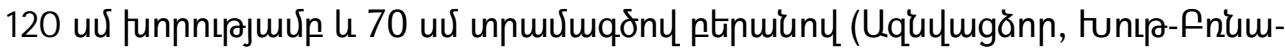
$2 \operatorname{tin}):$

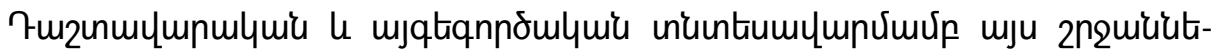

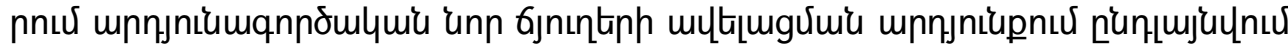

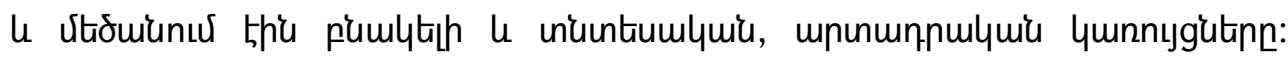

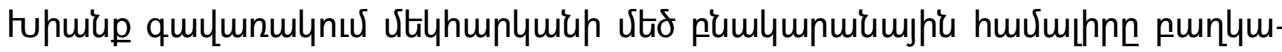




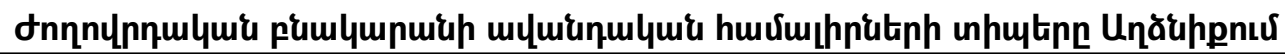

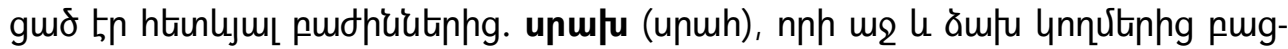

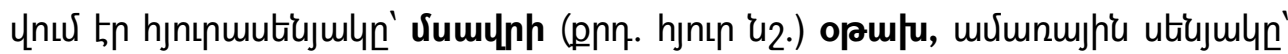

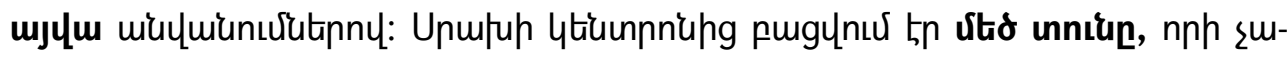

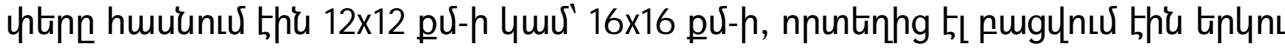

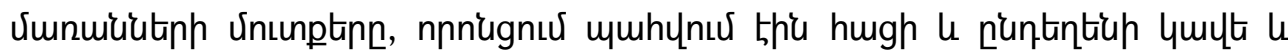

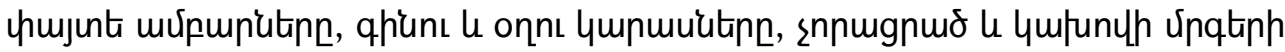

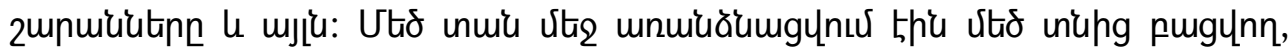

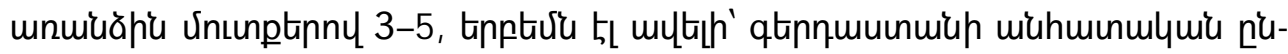

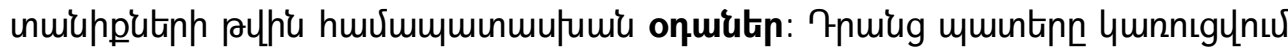

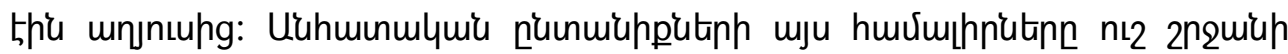

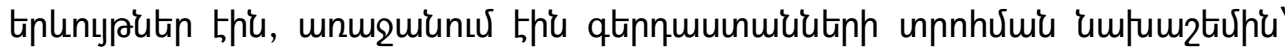

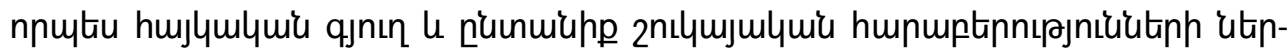
purhuiugrumu htinlumiup:

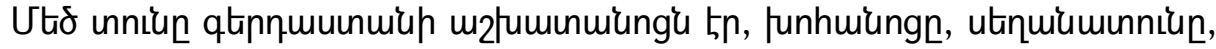

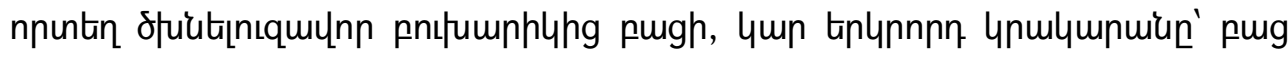

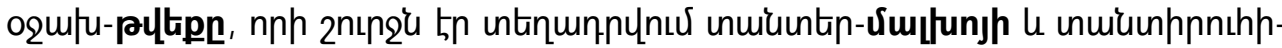

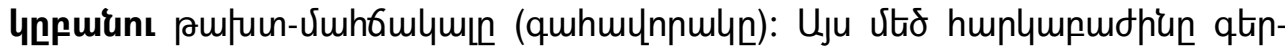

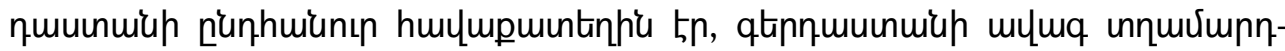

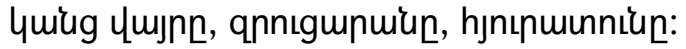

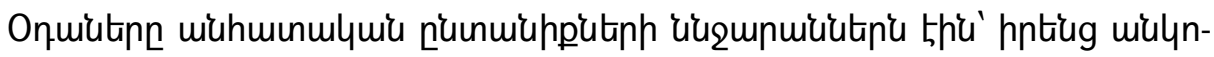

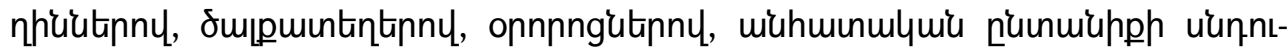

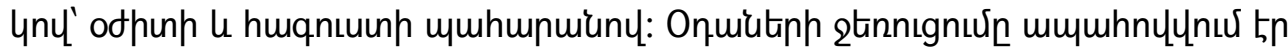

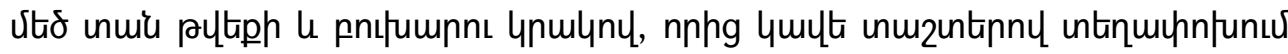

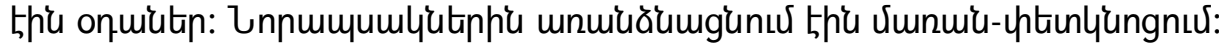

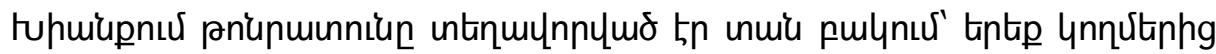

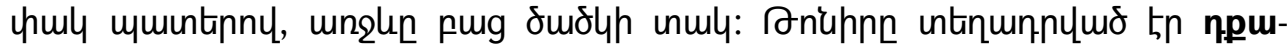

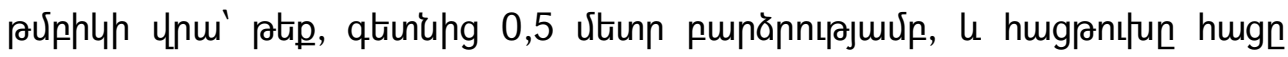

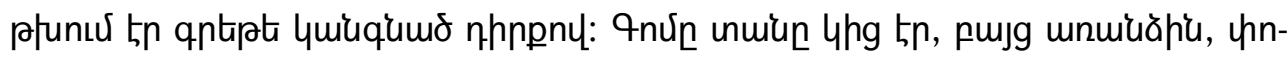

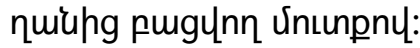

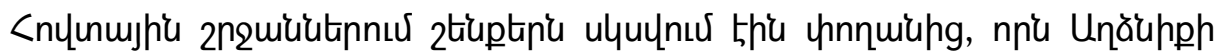

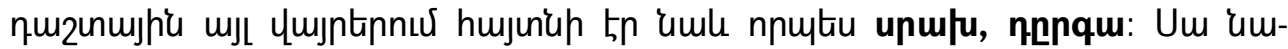
fumunuh 5 , nphg pugy

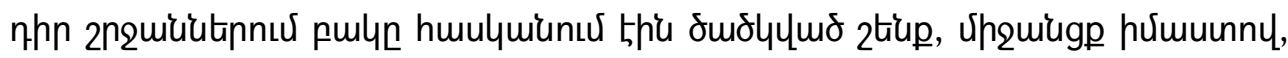

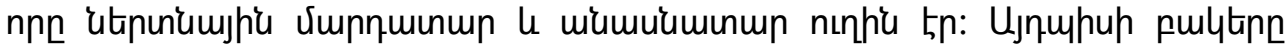

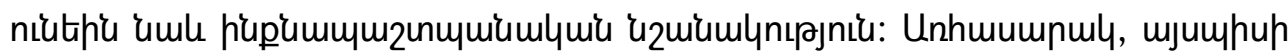


Uuhumbtunjuit $n$.

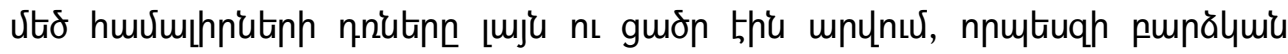

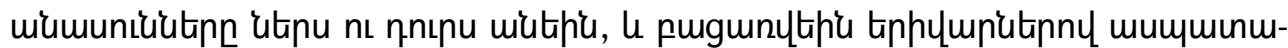

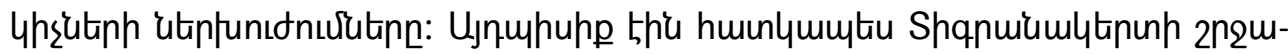

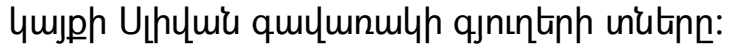

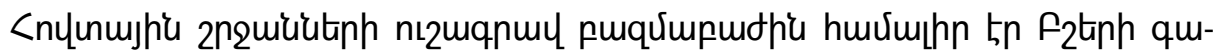

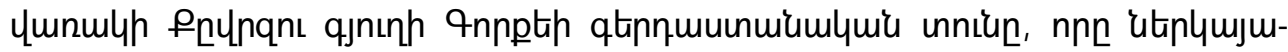

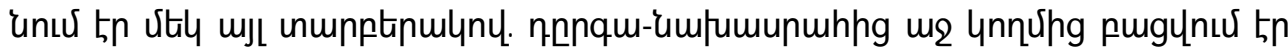

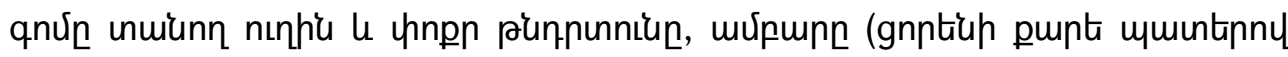

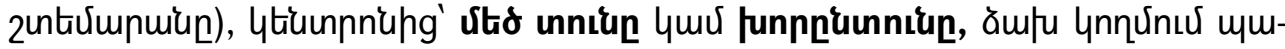

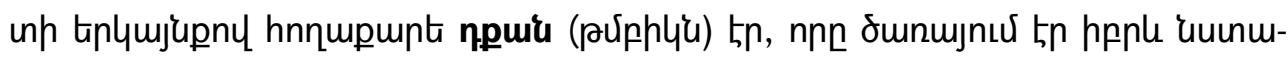

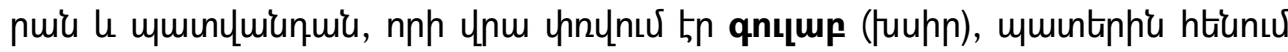

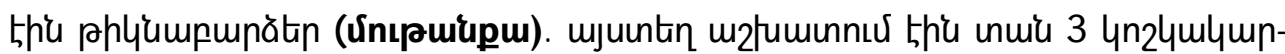

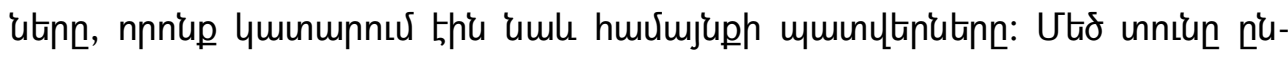

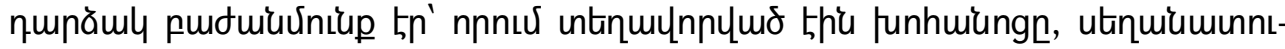

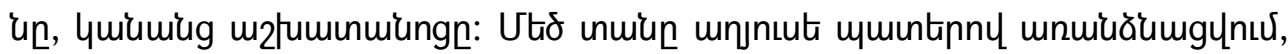

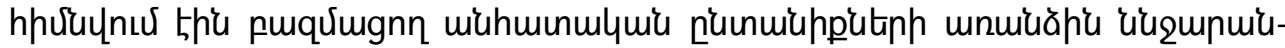

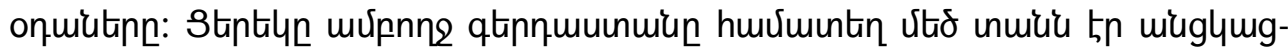

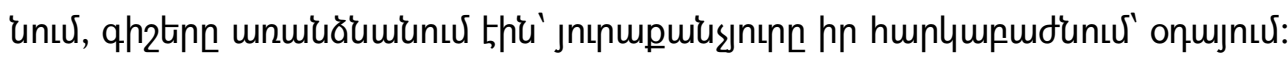

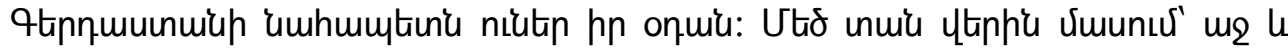

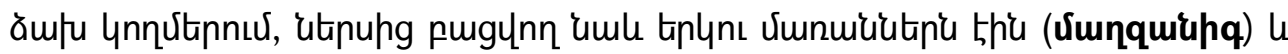

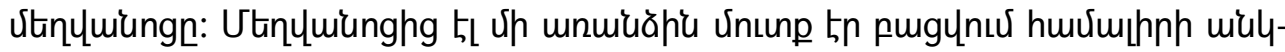

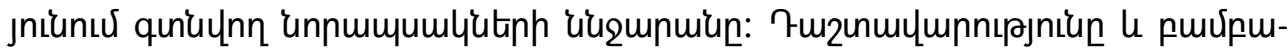

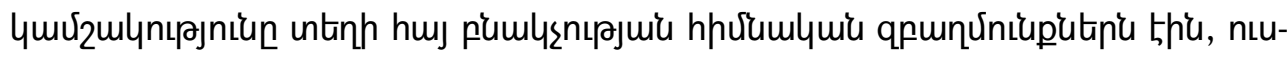

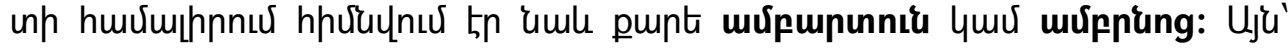

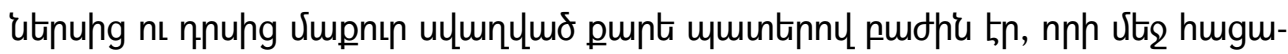

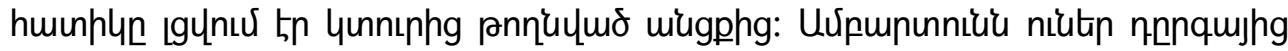

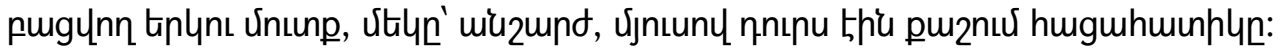

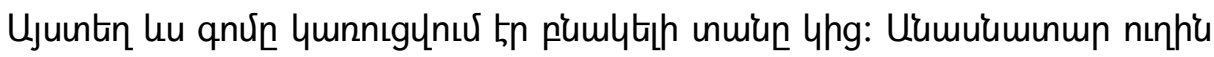

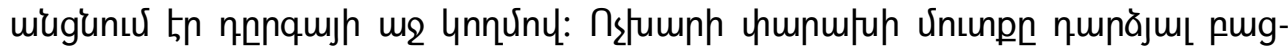

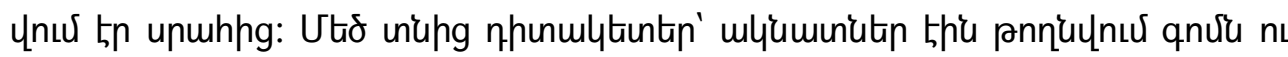

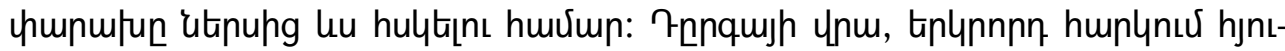

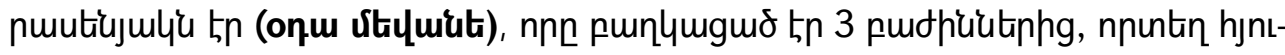

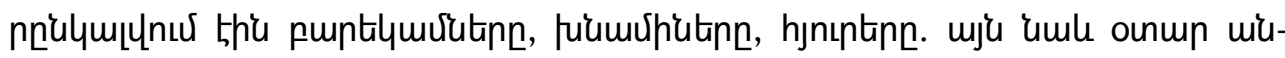

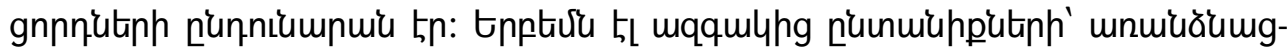




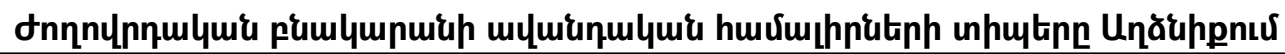

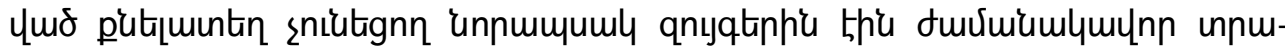

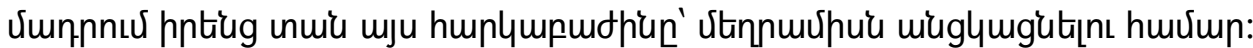

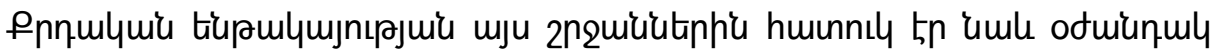

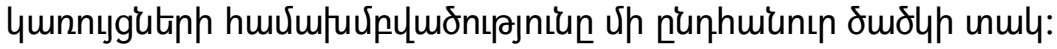

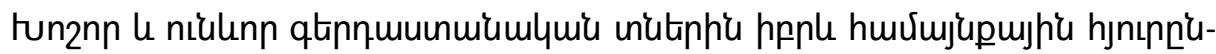

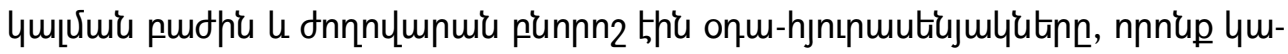

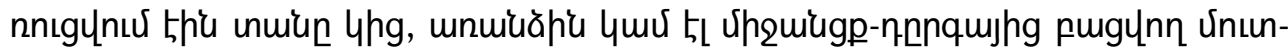

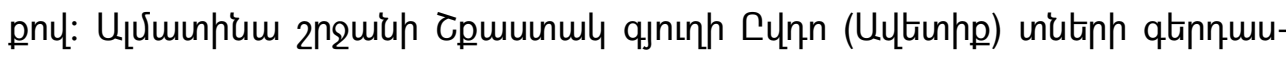

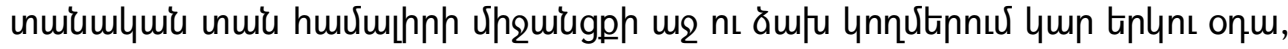

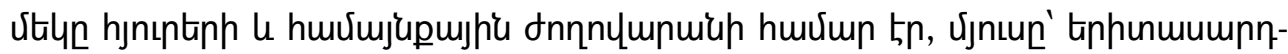

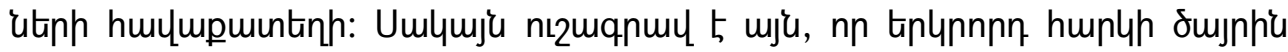

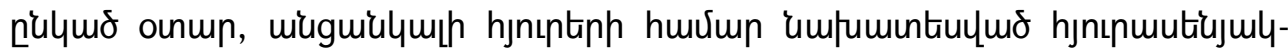

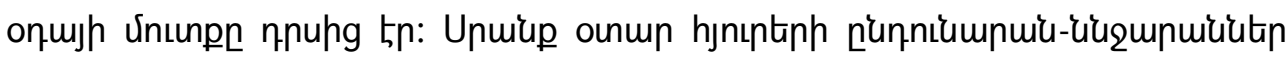
th'u' unwiǚumgy mor qtinnuuunuiuhg:

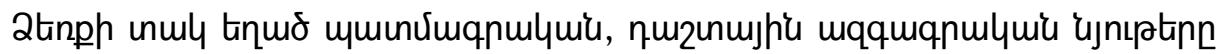

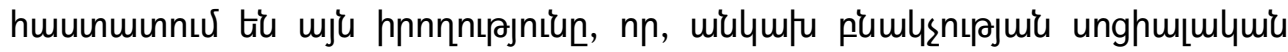

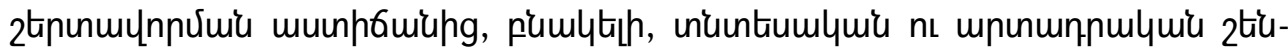

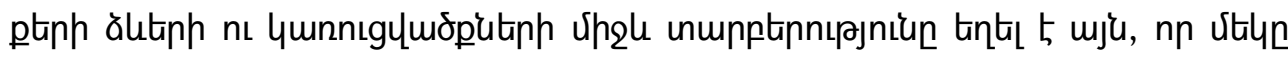

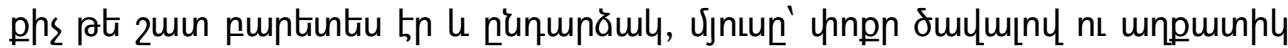

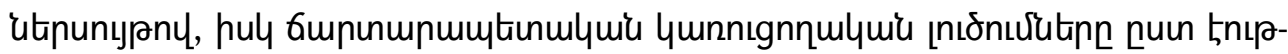

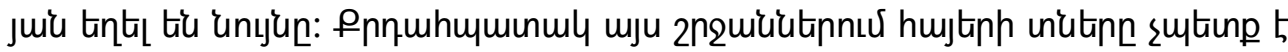

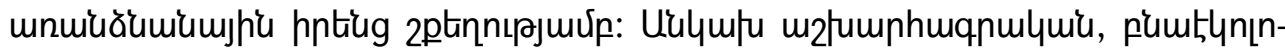

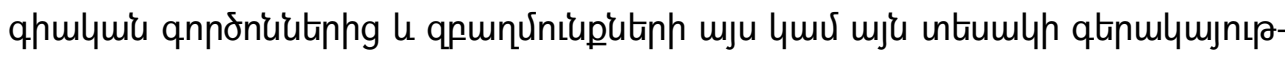

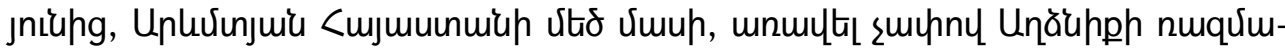

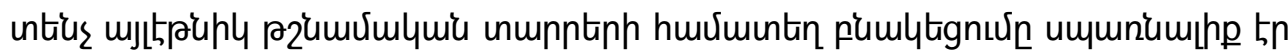

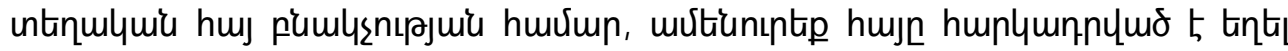

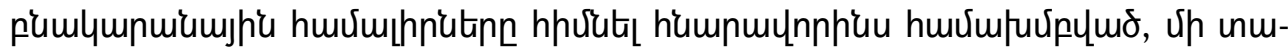

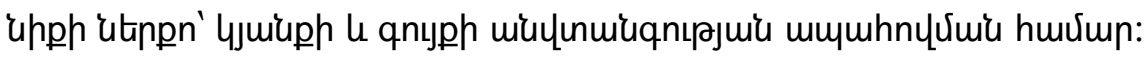

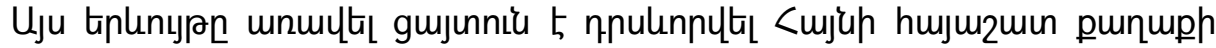

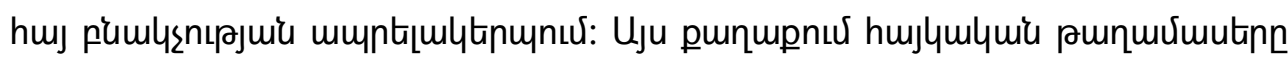

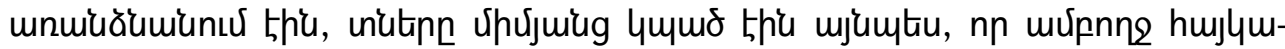

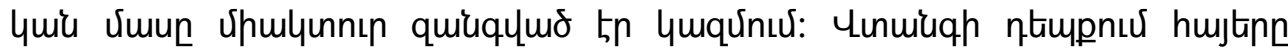
uunpuy wo thi humlytal unitipnus:

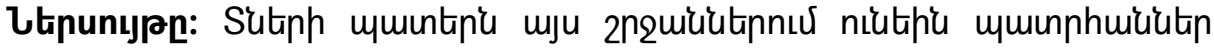

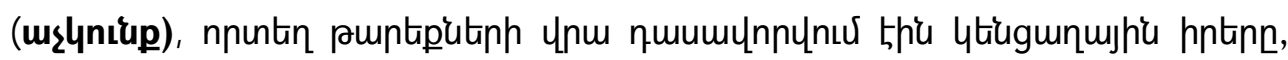


Umhumbtunjuis $\mathrm{n}$.

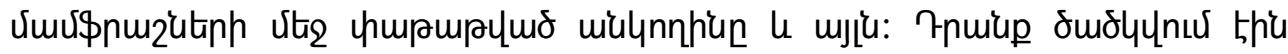

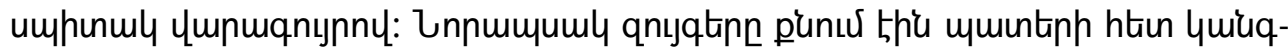

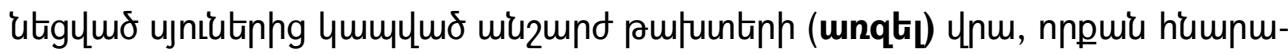

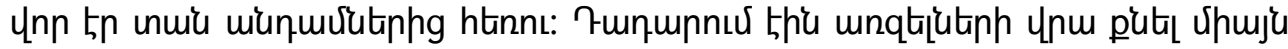

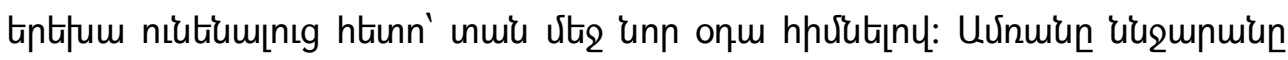
4unnเnน $5 n^{13}$ :

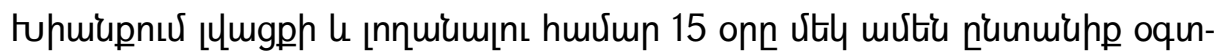

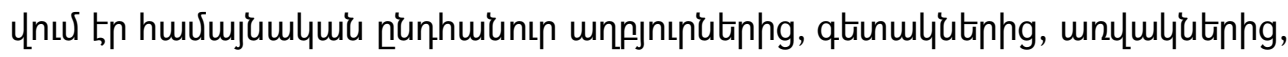

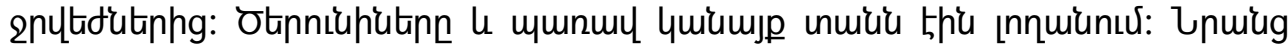
oqunus thiu guhts humuutatiu ne unghlyutinn:

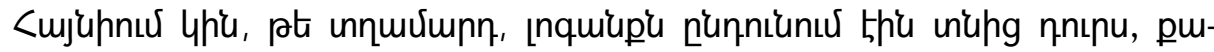

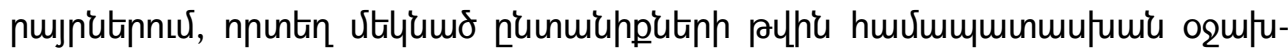

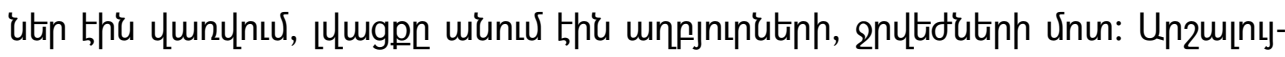

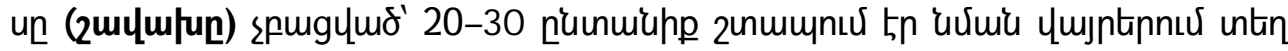

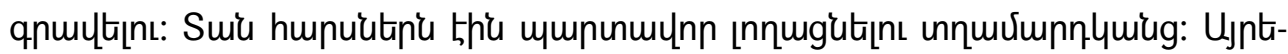

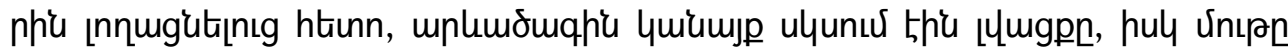

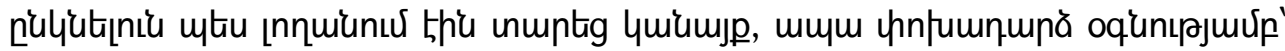

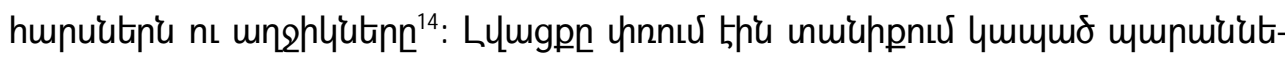
nhu:

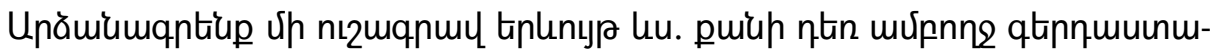

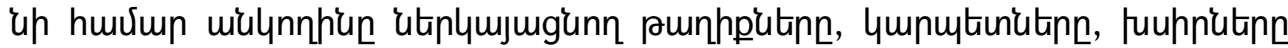

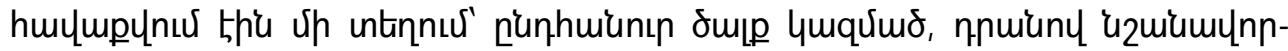

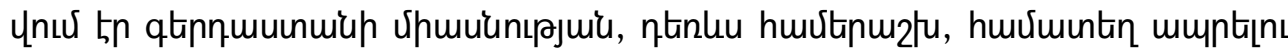

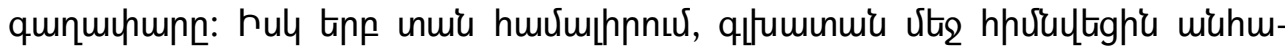

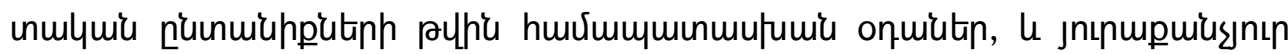

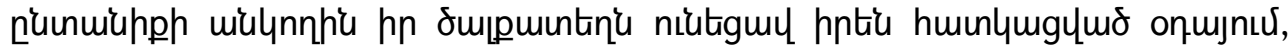

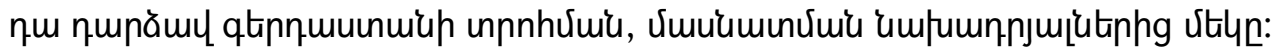

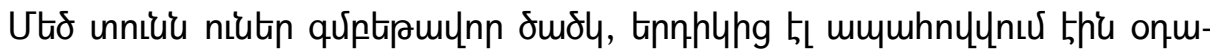

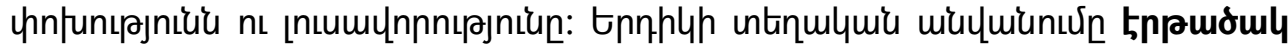

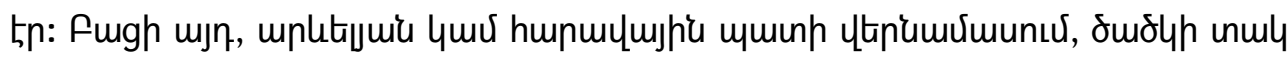

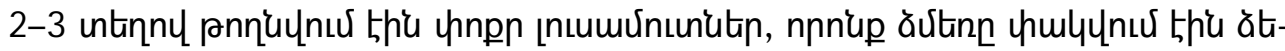
pnun prpnu:

${ }^{13}$ Stíu Uuhumuttunjứ 1985, un. 8, 89-91:

${ }^{14}$ St'u Umhwumtunjứ 1985, un. 8, 35-37: 


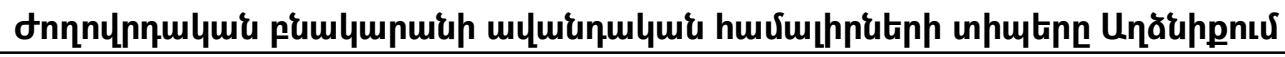

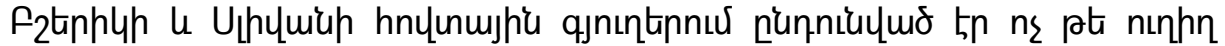

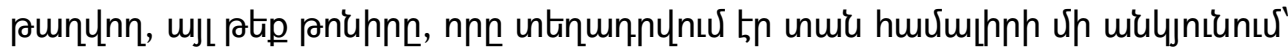

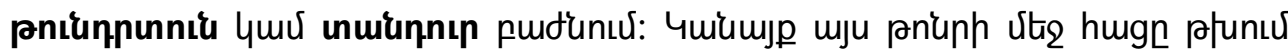

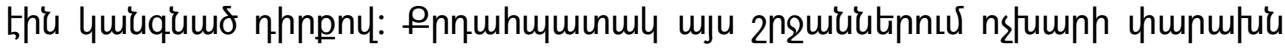

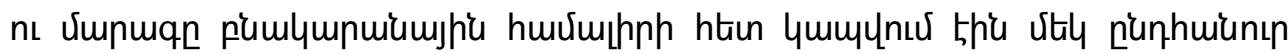
Ununpny $4^{15}$ :

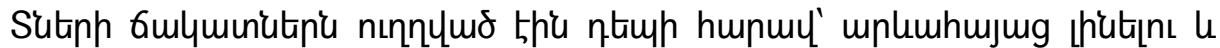

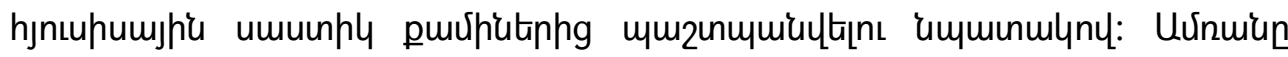

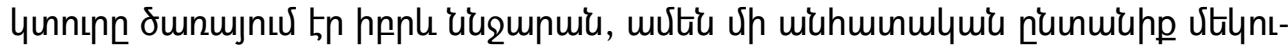

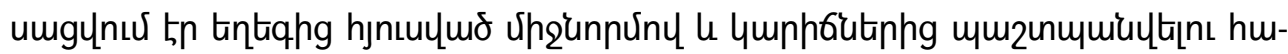

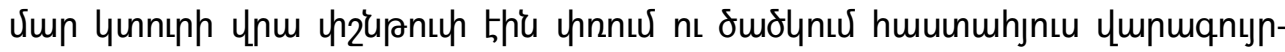
fuuhnny:

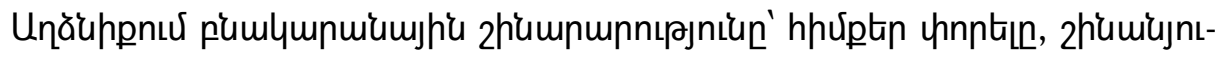

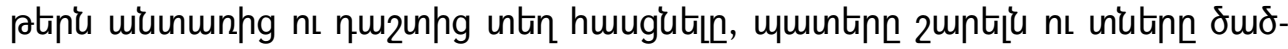

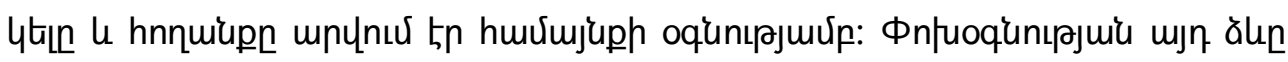

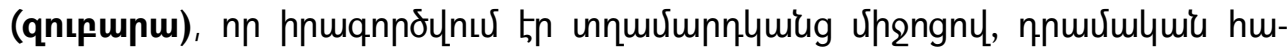

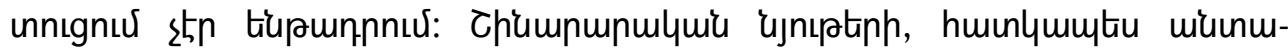

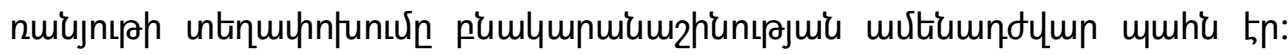

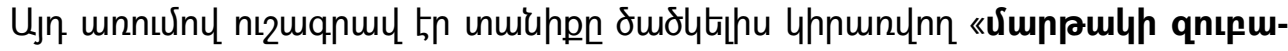

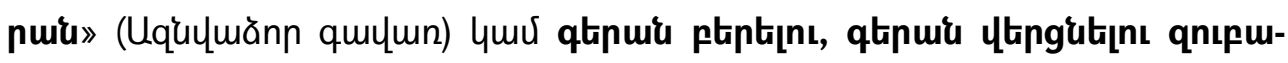

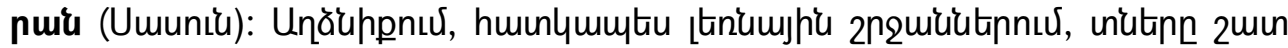

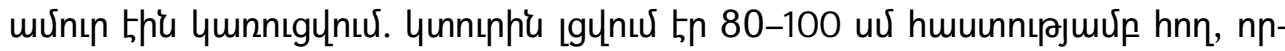

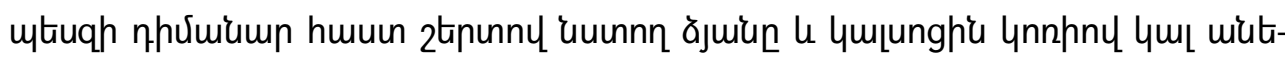

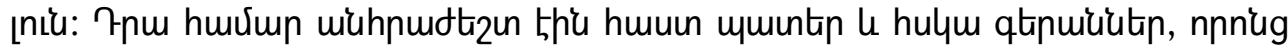

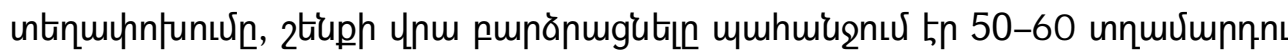

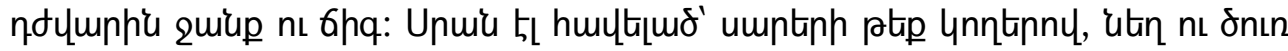

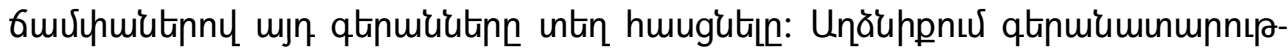

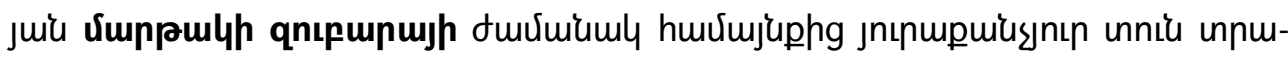

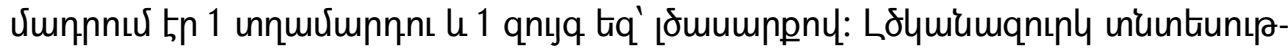

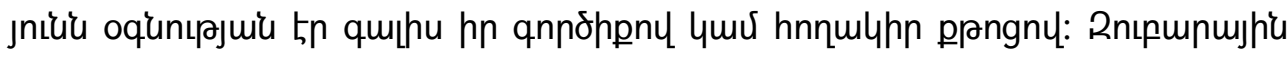

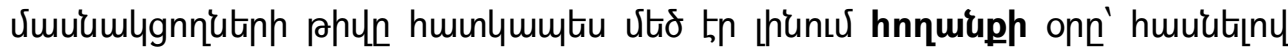

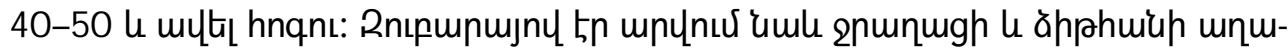

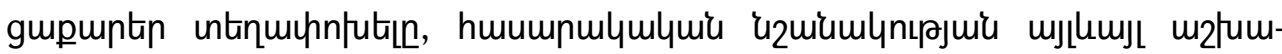

${ }^{15}$ Stíu Zuhumutinjuư 1985, un. 8, 89-90: 
Umhumbtunjuis $\mathrm{n}$.

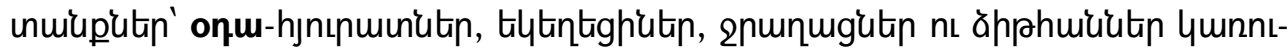

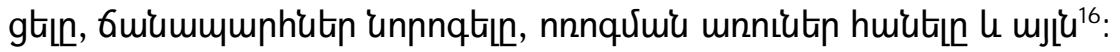

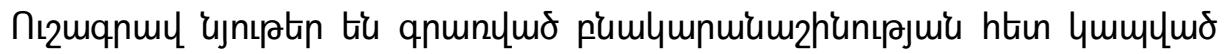

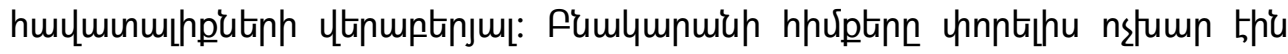

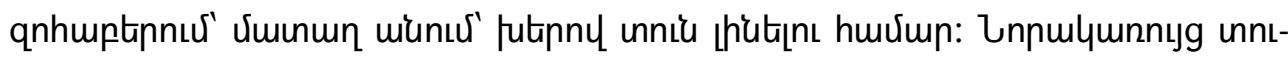

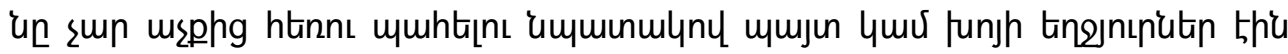

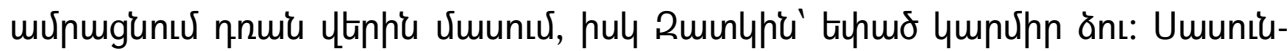

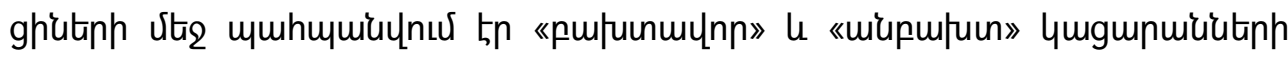
huчumunuhpn:

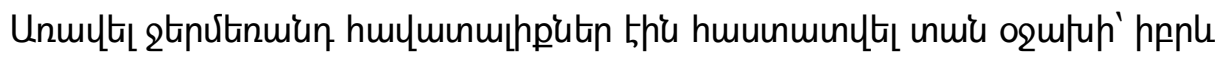

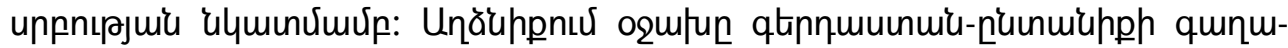

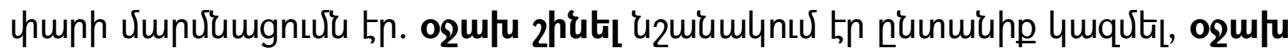

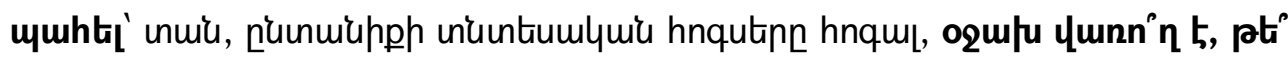

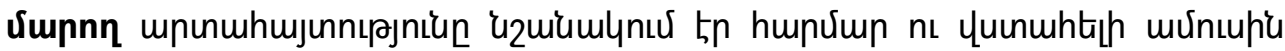

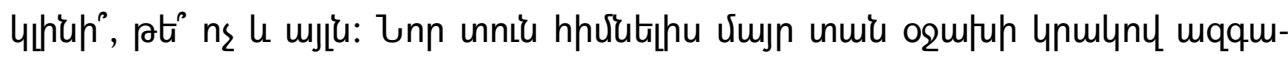

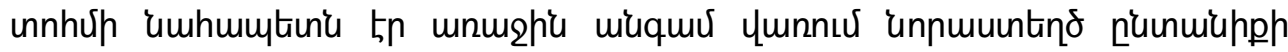

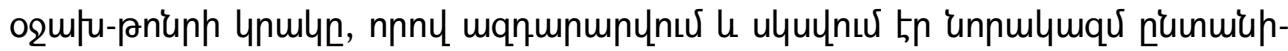

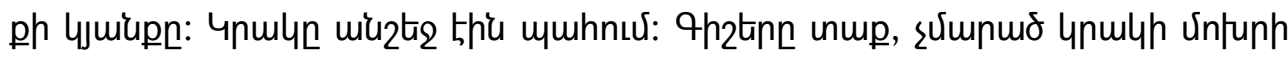

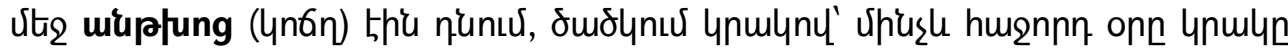

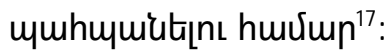

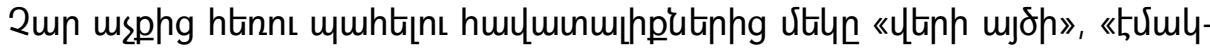

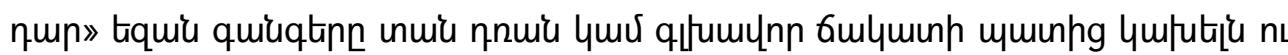

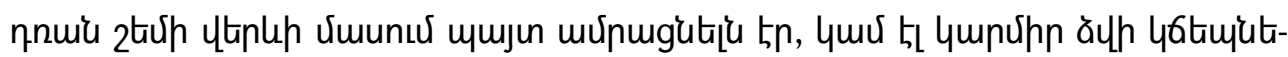

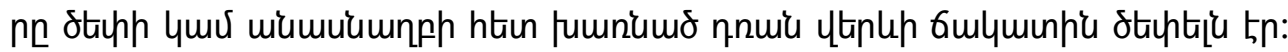

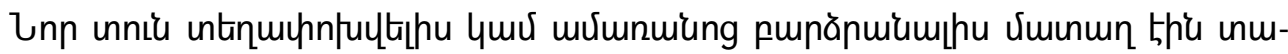

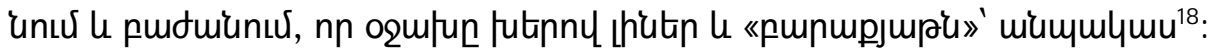

\section{tqnulyugnıpjnilititp}

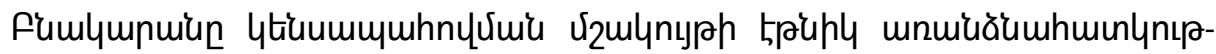

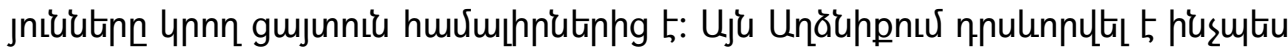

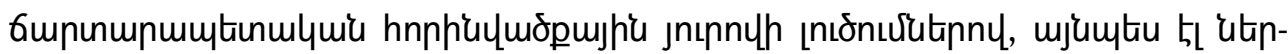

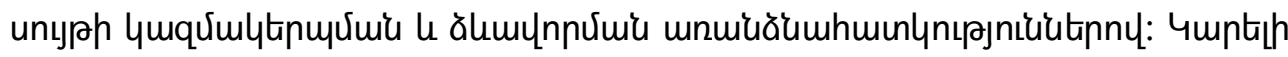

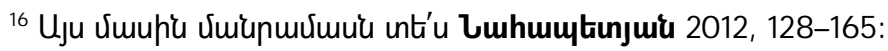

${ }^{17}$ St'u Uuhumutinjuiu 2020, qhnp 3, 230-242:

${ }^{18}$ Stíu Ttinnjuí 1965, 201-202:
} 


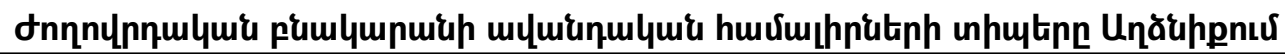

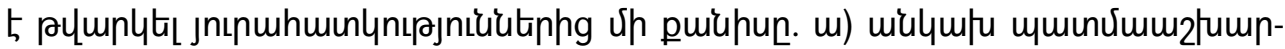

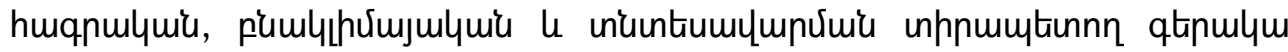

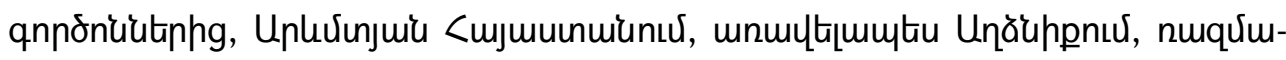

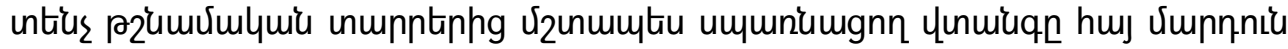

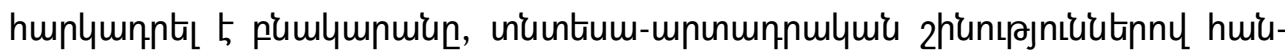

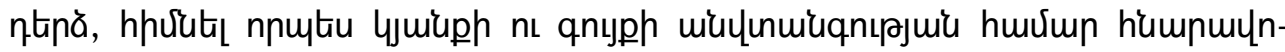

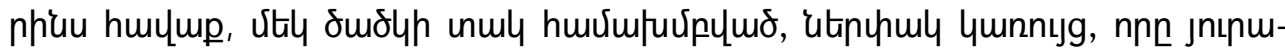

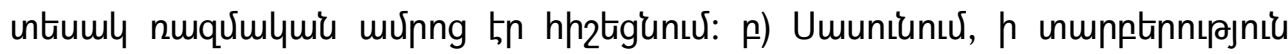

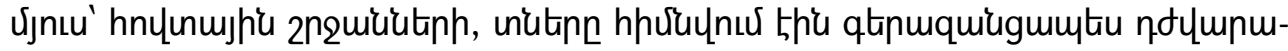

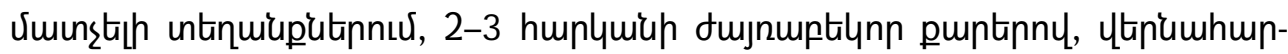

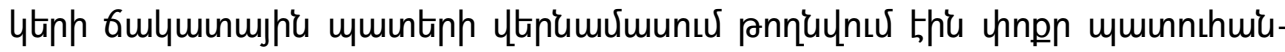

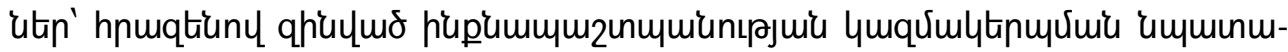

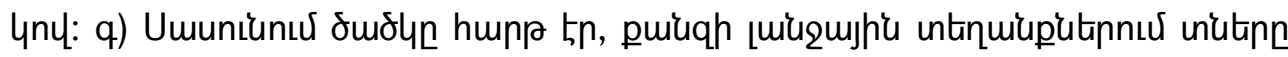

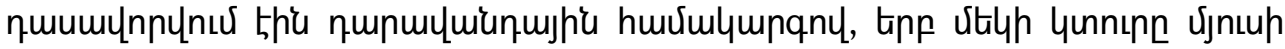

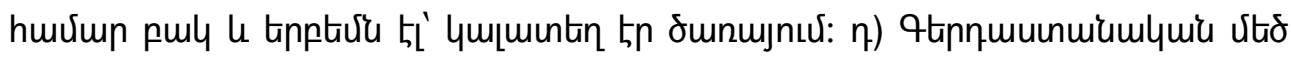

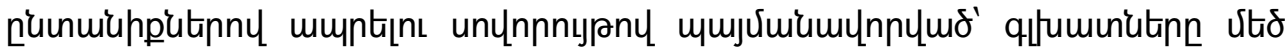

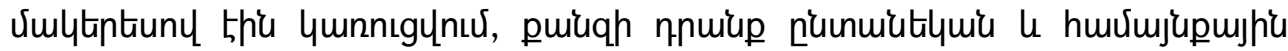

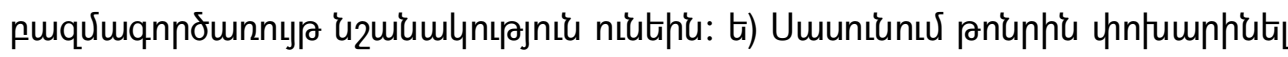

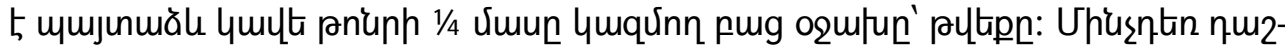

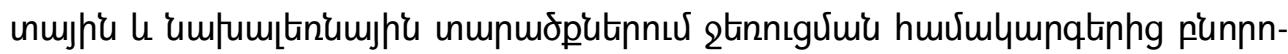

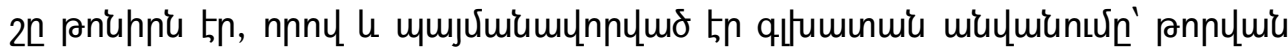

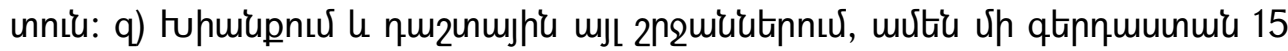

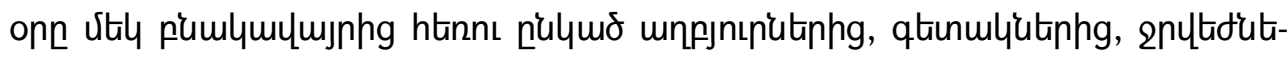

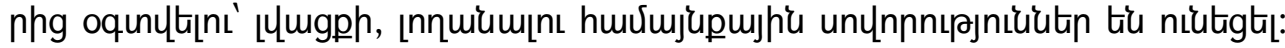

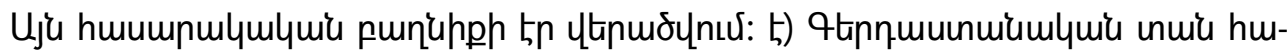

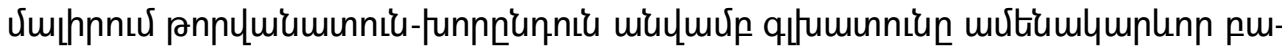

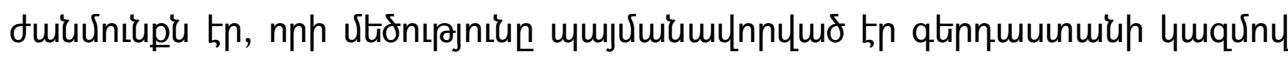

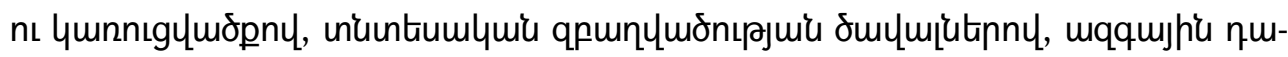

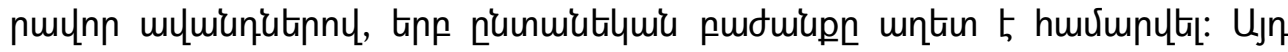

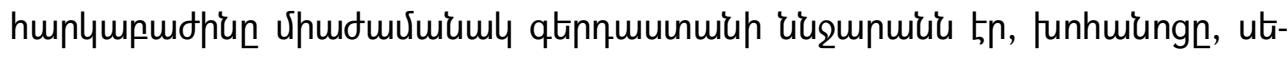

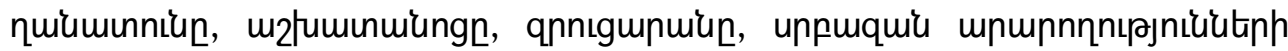

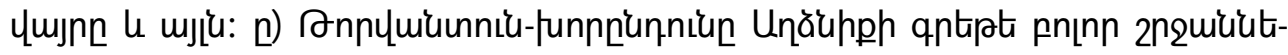

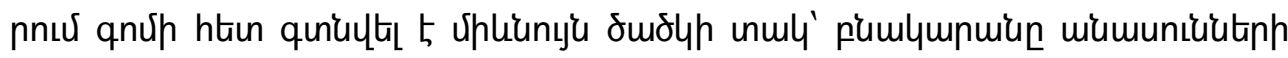

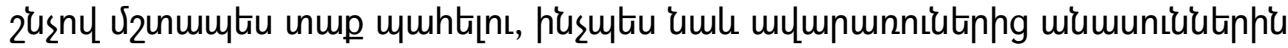

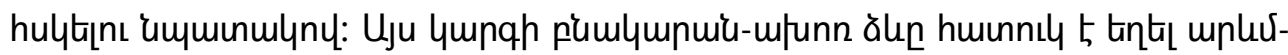




\section{Uuhumutinjuis $\mathrm{n}$.}

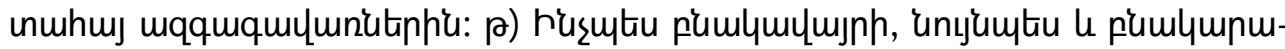

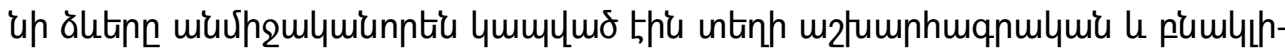

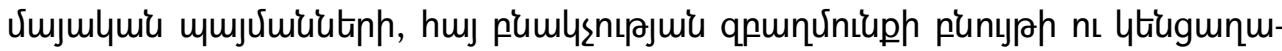

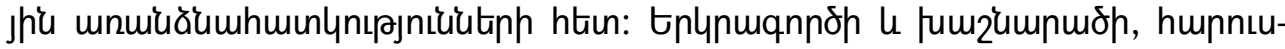

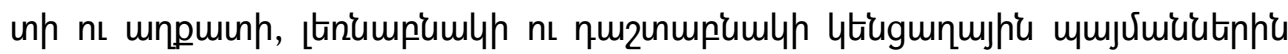

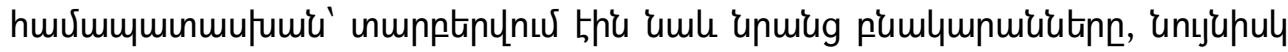

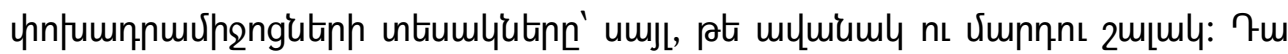

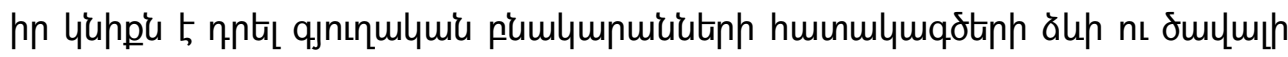

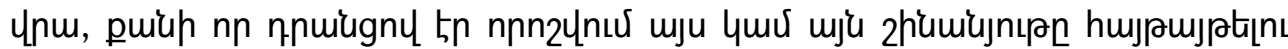

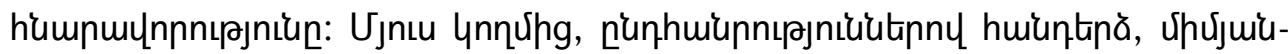

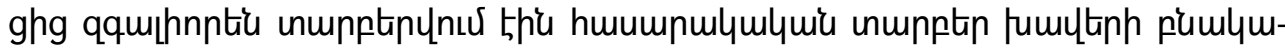

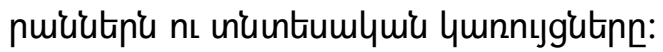

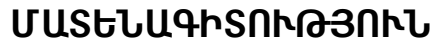

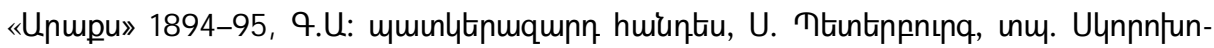
nnulh:

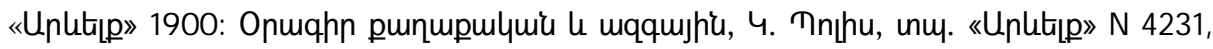
1903, N 5221

«Untıtı|p» 1903, กınunnh hp2uunulyutinn, № 5221:

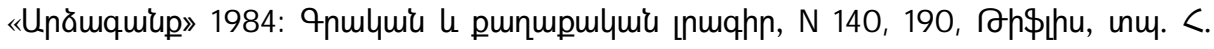
Uununhnnujuiugh:

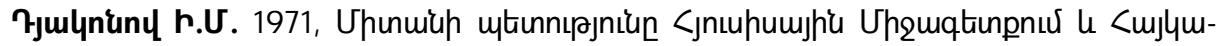

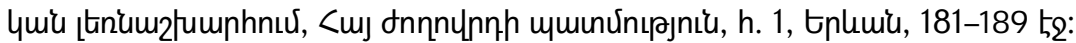

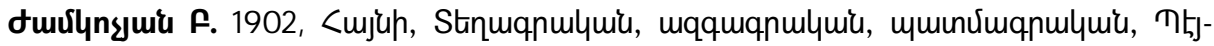
pnıр, unu. Soüpltiuiu, 457 t2:

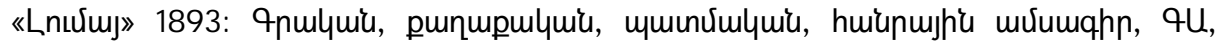
әि\$цhu, unu. 乙. Unujuiuh:

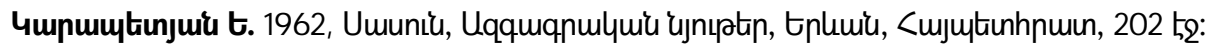

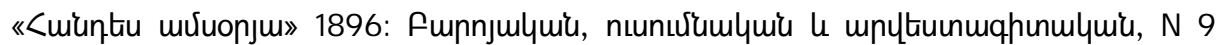

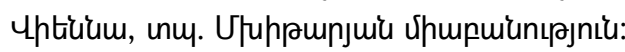

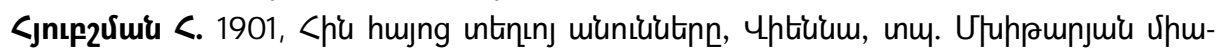
puiunıрјu'u, 449 52:

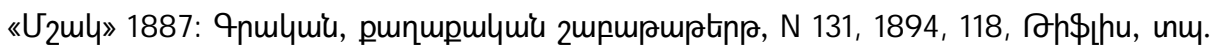

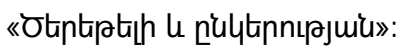

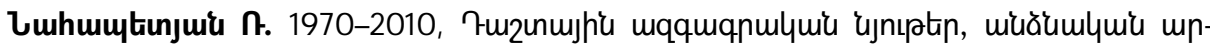
jupl, unun. 1-26:

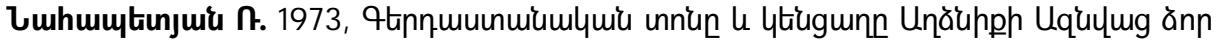

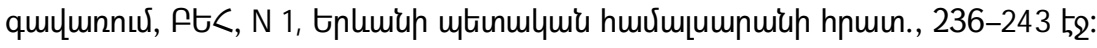




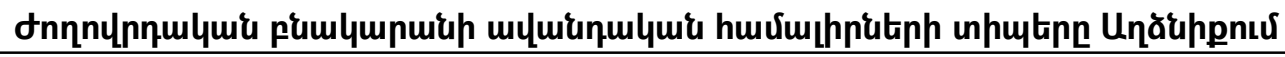

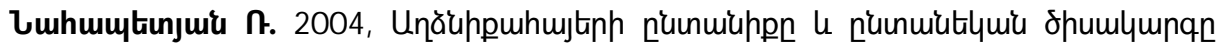

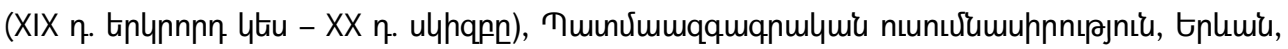

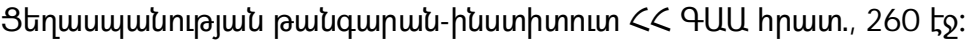

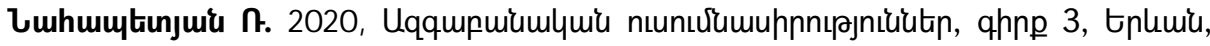
Shp hnuin., 394 to:

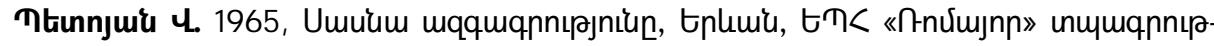
jniu, 549 t5:

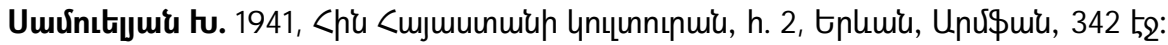

Umuniu 1894-95, «Unmpu» huiuntiu, qhnp U, Op\$phu hpuin.:

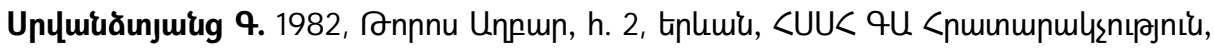
56352 :

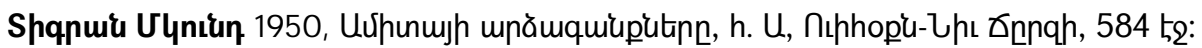

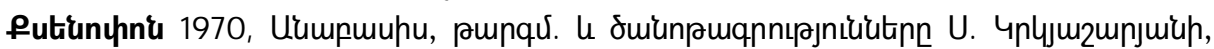
Enlumiu, <UU< qU hnum., 282 t2:

Харадзе Р. 1960, Грузинская семейная община, т. 1, Тбилиси, АН Груз. ССР, 190 с.

\section{ТИПЫ ТРАДИЦИОННЫХ НАРОДНЫХ ЖИЛЫХ КОМПЛЕКСОВ В АГДЗНИКЕ (XIX в. - начало XX в.)}

\section{НААПЕТЯН Р.}

Резюме

Ключевые слова: Агдзник, Сасун, горный населённый пункт, родовые населённые пункты, жилищные типы, родственные кварталы, самооборона.

Армянское село в Агдзнике до Геноцида в 1915 г. сохраняло древний обычай заселения родственными кланами, сосредоточенными в отдельном населённом пункте, что было продиктовано социально-экономическими и оборонительными соображениями. Следовательно, одной из характерных особенностей населённого пункта была укомплектованность жилищ под одной общей крышей.

Сельские населённые пункты представляли собой прилегающие друг к другу, связанные друг с другом изнутри и снаружи (посредством открывающегося по соседству входа) жилые комплексы, крыши которых прев- 
Umhumutunjuir $\mathrm{n}$.

ращались в тропинки, площадки для коллективных работ, проведения собраний и торжеств.

Обычай совместного проживания кланами способствовал формированию родовых населенных пунктов.

\section{TYPES OF TRADITIONAL RESIDENTIAL COMPLEXES OF AGHDZNIK}

(in the $19^{\text {th }}$ and at the beginning of the $20^{\text {th }}$ centuries)

\section{NAHAPETYAN R.}

\section{Summary}

Keywords: historical Agdznik, Sasun, mountain settlement, tribal settlements, housing types, related quarters, self-defense

Before the Genocide of Armenians in 1915, the Armenian village in Agdznik preserved the ancient custom of settling kindred clans in separate settlements. This was conditioned by socio-economic and defense considerations. Consequently, one of the characteristic features of the settlement was the cohesion of housing complexes under one common roof.

Rural settlements were residential complexes with houses adjoined to each other. The latter were connected to one another from within and from outside (through an entrance to the neighbouring house). Their roofs turned into pathways, ar eas for collective work, meetings, celebrations.

The custom of cohabitation by clans contributed to the formation of clan settlements. 